\title{
Periodontal Disease and "Oral Health" in the Past: New Insights from Ancient Sudan on a Very Modern Problem
}

\author{
Rebecca Whiting ${ }^{1,2^{*}}$, Daniel Antoine ${ }^{2}$, and Simon Hillson ${ }^{1}$ \\ ${ }^{1}$ University College London, UK \\ ${ }^{2}$ The British Museum, London, UK
}

Keywords: Periodontal disease, Kerr method, interdental septum, Sudan, bioarchaeology

\begin{abstract}
As one of today's major oral health issues, periodontal disease affects populations worldwide. Here, methods used to record its past prevalence are reviewed, indicating that clinical and bioarchaeological research offers strong support for the Kerr method, recording morphological changes of the interdental septum as a means of identifying periodontal disease. Using Kerr's approach, four assemblages from Sudan dating from the Neolithic, Kerma, and Medieval periods are examined to track the prevalence of the disease through time. Results show a significantly lower prevalence and limited oral distribution of periodontal disease in the Neolithic period. At Medieval period sites, significantly higher prevalence is seen with increasing age in male individuals, which is not seen in females. With no patient history and the cumulative effects of a dynamic and episodic disease, the effects of periodontal disease on the concept of 'oral health' may be hard to apply in archaeological remains. At best it provides an insight into the periodontal status at death - a 'snapshot' that reveals differences across the mouth, over time and between sexes in these Middle Nile Valley collections, giving insight into periodontal status in this region and advancing current understanding of the history of periodontal disease.
\end{abstract}

Today, periodontal disease is a major health issue worldwide, with the World Health Organisation (WHO) reporting it as the eleventh most prevalent disease in the world (Global Burden of Disease, 2017). Periodontal disease is the inflammation of the gingival (gum) tissues leading to destruction of the supporting soft and hard tissues of the teeth. It is one of the foremost causes of tooth loss and without access to dentures or dental implants edentulism can become a huge problem (Petersen et al., 2005). Recent investigations show that both gingivitis (the inflammation of the gums) and periodontal disease (Global Burden of Disease, 2017) are highly prevalent. In nearly every region of the globe, the Community Periodontal Index (CPI), aimed at monitoring periodontal health, shows that $40-60 \%$ of $35-44$ year olds have small or large periodontal pockets (CPI scores 3 or 4), due to inflammation, loss of attachment of the gingivae and possible bone loss. This is accompanied by a 35$60 \%$ gingivitis prevalence (CPI scores 1 and 2; [Global Burden of Disease, 2017, p. 2189]). Gingivitis is also found to be highly prevalent in adolescents between the ages of 15-19 (Global Burden of Disease, 2017; Petersen et al., 2005). Periodontal disease, its distribution and effects on systemic - as well as oral - health, are a current and global concern (Barnett, 2006; Bawadi et al., 2011; Geethika \& Chava, 2016; Hajishengallis \& Korostoff, 2017; Hu- joel \& Lingström, 2017; P. Petersen \& Ogawa, 2012). Bioarchaeological methods can be used to explore the prevalence of this disease in past populations and, as shown here, provide new data on Nile Valley archaeological collections against which modern prevalence and distribution rates can be compared. This new study investigates if the Kerr method (Kerr, 1988), which has seldom been applied to archaeological assemblages, is an appropriate method to record periodontal status. It also assesses differences in the prevalence of periodontal diseases between the Neolithic and Medieval periods in the Middle Nile, if these results vary by sex and age and how this study compares to published data from other archaeological assemblages and modern populations. Few large-scale bioarchaeological studies of periodontal disease in the Nile valley have been published and this study adds to our understanding of its past prevalence in a manner that accounts for the variable preservation of archaeological collections, allowing comparisons with modern clinical data.

\footnotetext{
*Correspondence to:

Rebecca Whiting

University of College London

The British Museum

rwhiting@britishmuseum.org
} 


\section{Materials}

The Nile Valley offers some of the largest pre-modern cemetery collections found in Africa (Friedman, 2007; Irish, 2010; Salvatori \& Usai, 2008b). Large skeletal assemblages from a range of time periods were recently recovered in Sudan (Welsby, 2003), several of which were generously donated by Sudan's National Corporation for Antiquities and Museums and are currently curated at The British Museum. These include two large Medieval burial sites from the Fourth Cataract region of the Middle Nile Valley (Figures 1 and 2) dating to the Medieval (c. AD 550 -1500 - site 3-J-23) and the Late Medieval (c. AD 1100-1500 - site 3-J-18) periods. Preservation is excellent at both sites, including some remarkable examples of natural mummification, providing insights into the state of periodontal disease in pre-industrial Northeastern Africa. The older sites of H29 (Kerma Ancien - 2050-1750 BC) and R12 (Neolithic - 3500 BC) were also included to explore the

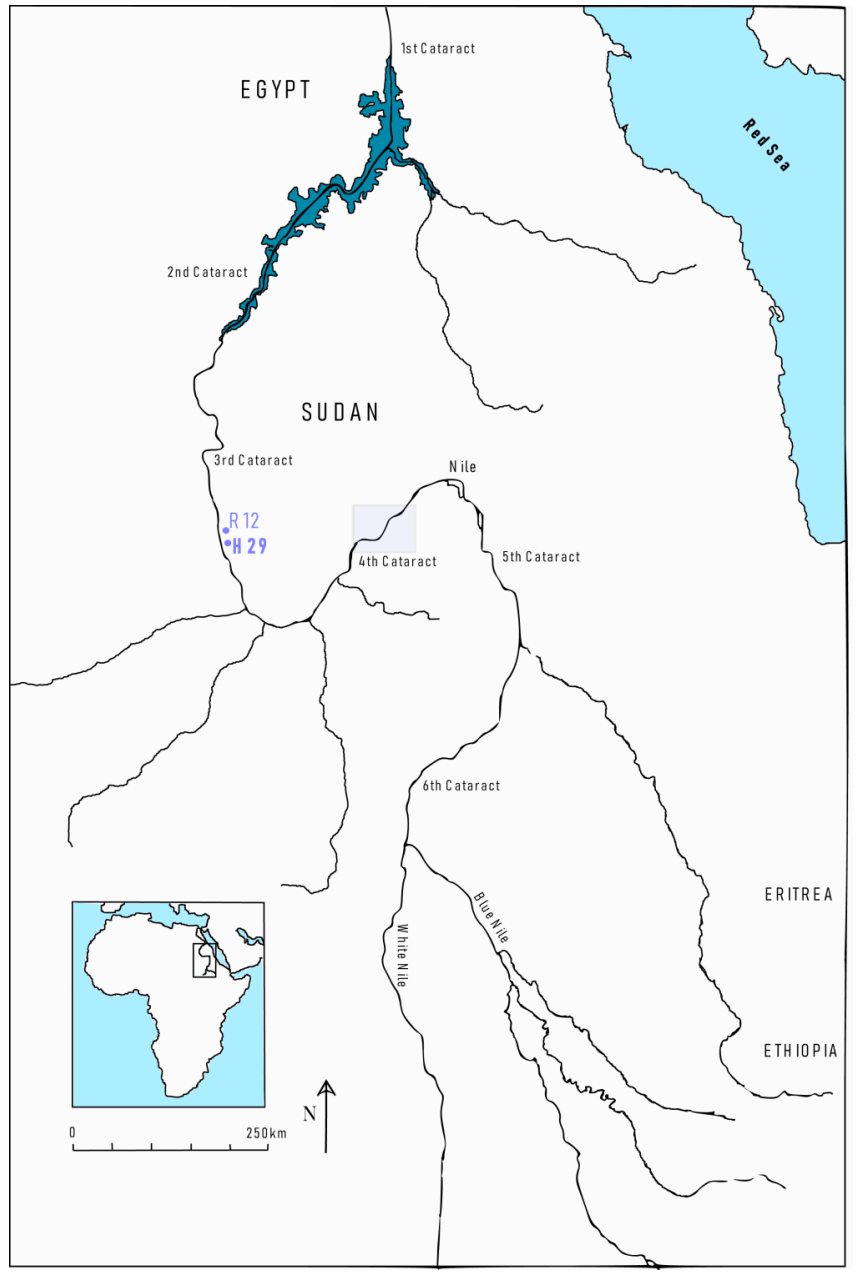

Figure 1: Map of the Nile Valley, from the First Cataract to south of the confluence of the White and Blue Niles, demonstrating the location of sites H29 and R12. The region of the $4^{\text {th }}$ Cataract, including sites 3-J18 and 3-J-23, is also highlighted within the box and is shown in greater detail in Figure 2.

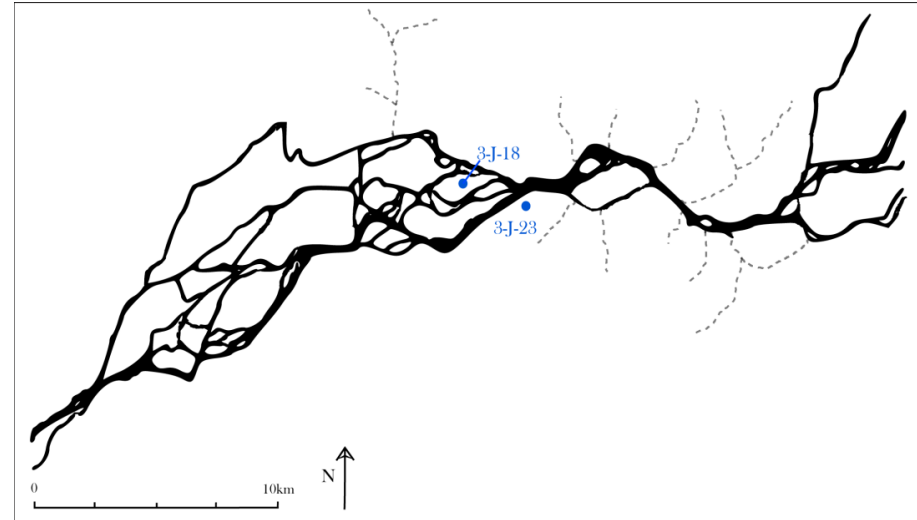

Figure 2: Map of the Fourth Cataract region, with the location of sites 3-J-18 and 3-J-23 shown. Original image copyright of A. Davies-Barrett.

progression of the disease over time and contextualise the data gathered within the wider temporal framework. Despite poorer preservation at the earlier sites, a reasonably high number of individuals were analysed for evidence of periodontal disease (Table 1 ). Table 2 shows the number of individuals included in the study by sex and age group. Both Medieval sites had proportionately different numbers of males and females in each age category. At 3-J -23 a greater number of females were assigned to the young adult category $(n=22)$. At 3-J-18 a greater proportion of males were assigned to the middle adult category $(n=31)$. Sites H29 and R12 had roughly equal numbers in each sex and age group. Where results have been divided by age and sex it should be noted that adolescents have been grouped into the young adult category while old adults have been grouped with middle adults. Sex estimations of probable female and female have been grouped together, as have probable male and male individuals. These grouping meant that the numbers involved were larger and more representative of the whole.

Table 1. Sites included in the current study, number of individuals and time period for each site are given

\begin{tabular}{ccc} 
Sites & $\mathbf{n}$ & Time period \\
3-J-18 & 111 & Late Medieval (AD1100-1500) \\
3-J-23 & 69 & Early Medieval (AD500-1000) \\
H29 & 62 & Kerma Ancien \\
R12 & 70 & \\
Total & 312 & \\
\hline
\end{tabular}


Table 2. Age and sex distributions for each site

\begin{tabular}{|c|c|c|c|c|c|c|c|}
\hline Site & & Adolescent & $\begin{array}{l}\text { Young } \\
\text { Adult }\end{array}$ & $\begin{array}{l}\text { Middle } \\
\text { Adult }\end{array}$ & $\begin{array}{l}\text { Old } \\
\text { Adult }\end{array}$ & Unknown Age & Total \\
\hline \multirow{4}{*}{$\underset{n}{\pi}$} & Male & - & 4 & 6 & - & 12 & 22 \\
\hline & Female & 1 & 4 & 3 & - & 3 & 11 \\
\hline & Indt. sex & - & 2 & 2 & - & 33 & 37 \\
\hline & Total & $\begin{array}{c}1 \\
(1.4 \%)\end{array}$ & $\begin{array}{c}10 \\
(14.3 \%)\end{array}$ & $\begin{array}{c}11 \\
(15.7 \%)\end{array}$ & $\begin{array}{c}- \\
(0.0 \%)\end{array}$ & $\begin{array}{c}48 \\
(68.6 \%)\end{array}$ & 70 \\
\hline \multirow{4}{*}{ 胥 } & Male & - & 8 & 9 & - & 2 & 19 \\
\hline & Female & - & 10 & 6 & - & 12 & 28 \\
\hline & Indt. sex & 2 & 2 & 1 & - & 10 & 15 \\
\hline & Total & $\begin{array}{c}2 \\
(3.2 \%)\end{array}$ & $\begin{array}{c}20 \\
(32.2 \%)\end{array}$ & $\begin{array}{c}16 \\
(25.8 \%)\end{array}$ & $\begin{array}{c}- \\
(0.0 \%)\end{array}$ & $\begin{array}{c}26 \\
(38.8 \%)\end{array}$ & 62 \\
\hline \multirow{5}{*}{ 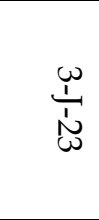 } & Male & 1 & 10 & 13 & - & 1 & 25 \\
\hline & Female & 2 & 20 & 10 & - & 1 & 33 \\
\hline & Indt. sex & 2 & 3 & 3 & - & 3 & 11 \\
\hline & Total & $\begin{array}{c}5 \\
770 \%)\end{array}$ & 33 & 26 & $\overline{-}$ & $\begin{array}{c}5 \\
770 \%\end{array}$ & \\
\hline & & $(7.2 \%)$ & $(47.8 \%)$ & $(37.8)$ & $(0.0 \%)$ & $(7.2 \%)$ & 69 \\
\hline \multirow{4}{*}{$\frac{\underset{1}{1}}{\stackrel{\vec{\omega}}{\infty}}$} & Male & - & 15 & 30 & 1 & 1 & 47 \\
\hline & Female & 6 & 23 & 21 & 2 & 3 & 55 \\
\hline & Indt. sex & 1 & 5 & 1 & - & 2 & 9 \\
\hline & Total & $\begin{array}{c}7 \\
(6.4 \%)\end{array}$ & $\begin{array}{c}43 \\
(38.7 \%)\end{array}$ & $\begin{array}{c}52 \\
(46.8 \%)\end{array}$ & $\begin{array}{c}3 \\
(2.7 \%)\end{array}$ & $\begin{array}{c}6 \\
(5.4 \%)\end{array}$ & 111 \\
\hline
\end{tabular}

These skeletal collections provide a unique opportunity to investigate periodontal disease in groups from a range of environmental, social, and cultural backgrounds. The Neolithic period in Nubia was characterised by semi-nomadic pastoralism combined with hunting and gathering (Bard, 2008; Gautier \& Van Neer, 2011; Hassan, 1986; L. Krzyżaniak, 2004; Wengrow et al., 2014). Increasing social complexity may have led to a range in craftsmanship, much of which could have involved the use of the mouth and dentition (Haaland, 1987; A. Krzyżaniak, 2011; Salvatori \& Usai, 2008a). During the Kerma period, small sedentary groups appear to have formed and there is evidence for urbanisation and socioeconomic centralisation at the town of Kerma (Bonnet, 2004, 2010; Chaix \& Grant, 1992). Pastoralism remained an important part of cultural practice and was also accompanied by an increase in the cultivation of crops (Chaix, 1984, 2007; Grant, 2002; D. Welsby, 1996). During the Medieval period settlements consisted of larger rural and urban groups, with centralised socioeconomic control, in particular as part of the Kingdom of Makuria in Upper Nubia (Godlewski, 2010; D. Welsby, 2002; D. Welsby \& Daniels, 1991).

There is also a pattern of increasing aridity across the Saharan region from the Middle Holocene (5000 BC) onwards (Kuper \& Kröpelin, 2006; Kuper et al., 2007; Macklin \& Woodward, 2001; Welsby, Macklin, \&
Woodward, 2002). Before and during the Neolithic, shifting rain-belts and higher humidity meant that Upper Nubia was a savannah-like environment and swamps and marshes may have been present, particularly in the areas surrounding the river, with paleochannels running into and around the main tributary of the Nile. This wetter environment underwent progressive desertification and, by around $1500 \mathrm{BC}$, was similar to the desert landscape of modern northern $\mathrm{Su}$ dan (Kuper \& Kröpelin, 2006, p. 806). The sites examined here represent a range of ecological niches. 3-J-18 was located on Mis Island, within the rocky and changeable land of the Fourth Cataract, and nearby 3-J23 was situated on the banks of the Nile (Thomas, 2008; Welsby, 2003, 2012). Both H29 and R12 were in the Northern Dongola Reach, further downstream than the Fourth Cataract, after the Nile turns north towards the Third Cataract. Site H29 was between the Alfreda and Hawawiya Niles (paleochannels) (Welsby, 2001; Whiting, 2018) and R12 at the southern end of the Seleim basin - a natural basin where water collected during high flood and rain fall (Salvatori \& Usai, 2008b). Differing environmental pressures and socio-cultural practices may have influenced the disease status, immune responses, behaviour, and diet of the individuals living in these different areas of the Middle Nile, which may have led to differences in the prevalence rate of periodontal disease. These collections allow for valuable 
comparisons at key points in time that may reveal shifts in 'oral health' and disease load. Results will also be compared with similar studies from around the globe, further aiding our modern understanding of the social, environmental and biological factors that affect susceptibility to periodontal disease and changes to the state of oral health over time.

\section{Clinical and anthropological background}

Periodontal disease is the result of the body's immune response to the long-term presence of large numbers of microorganisms in dental plaque deposits on the teeth. It is a hypersensitive reaction in which the immune response damages the tissues of the periodontium. In their seminal paper, Page and Schroeder (1976) described the four stages of periodontal disease as they were understood at the time, the main notions of which are still relevant to this day:

The initial lesion is described as inflammation and vascularisation involving infiltration of neutrophils (elements of the immune system) through the gingival tissue to the junctional epithelial cells lining the periodontal pocket (the periodontal pocket is formed around the tooth as the supporting tissues are destroyed). This is accompanied by movement of other immune elements such as T-cells, into the area but few B-cells.

The early lesion sees a change to macrophage and T-cell domination with lymphocyte proliferation and the beginnings of a loss of connective tissue, such as the periodontal ligament.

The established lesion involves further collagen (connective) degradation, detachment of the periodontal ligament and a clear increase in $B$ -cell involvement.

The advanced lesion is associated with alveolar bone loss and a further increase in B-cell proliferation.

The authors also noted that the apical extension of junctional epithelial cells leads to an extension/ expansion of the periodontal pocket, and that a susceptible host was necessary for the progression of the disease at all stages. As observed by Hajishengallis and Korostoff (2017), these concepts are still correct and relevant today. Advances since Page and Schroeder's original paper include an increased understanding of the interaction of the innate and acquired immune system, as well as a greater appreciation of the role and "functional plasticity" - or changeability of the role - of neutrophils in the initiation of the immune response and progression to per- iodontitis (Hajishengallis \& Korostoff, 2017, p. 119). This latter point highlights the importance of neutrophil homeostasis, with the related immunodeficiency or the overstimulation of these cells leading to destructive periodontitis (Cekici et al., 2014; Kornman, Page, \& Tonetti, 1997). Since Page and Schroeder's work, a clearer understanding of the interactions and synergism of episodes of immune response and bone formation and resorption has also been made - a field known as osteoimmunology. This has shown that T-cells and B-cells express RANKL (signalling protein) that contribute to the process of osteoclastogenesis, tipping the balance of bone homeostasis towards resorption (Kikuta et al., 2013). Many advancements in the understanding of this disease process were set out in a series of papers penned in part by one half (Page) of the original duo of Page and Schroeder (Darveau, Tanner, \& Page, 1997; Dennison \& Dyke, 1997; Kornman et al., 1997). These subsequent papers highlight the dynamic nature of the disease as it goes through periods of progression and healing, with destructive lesions developing early on in life in some cases, or much later in others, and the role of host susceptibility in its progression.

Clinical methods used to record and monitor periodontal disease and gingivitis have changed little over the past decades. The study by Belting, Massler, and Schour (1953), of over 5000 men from Chicago, measured the distance between the cemento-enamel junction (CEJ) and the alveolar crest (AC) using a dental probe to determine the point of alveolar attachment within the periodontal pocket. A measurement of $>2 \mathrm{~mm}$ was deemed to indicate bone loss resulting from periodontal disease. Additionally, gingival inflammation was recorded as bleeding/ presence of pus in the periodontal pocket. The World Health-Organization (2013) published a similar method to establish periodontal health that utilises the same kind of dental probe. Gingival bleeding was scored as 0 (none) or 1 (bleeding upon insertion of probe), while periodontal pocket depth was assessed in increments: 0 (absence $<3.5 \mathrm{~mm}), 1$ (4-5mm depth), 2 ( $\geq 6 \mathrm{~mm}$ depth) (World-HealthOrganization, 2013, pp. 48-50). This clinical approach is commonly used to diagnose periodontal disease in both humans and animals (Björnsson et al., 2003; Person, 1961; Tilakaratne et al., 2000; von Wowern, Klausen, \& Kollerup, 1994; Watson, 1994). Radiography has also been used to determine alveolar resorption. Papapanou, Wennström, and Gröndahl (1988) looked for both 'horizontal' and 'vertical' bone loss. Horizontal bone loss refers to the loss of height in the alveolar crest while maintaining a nor- 
mal periodontal ligament space between root and socket. Vertical bone loss denotes a morphological change in the vertical edges of the alveolar crest where the ligament space is expanded through vertical bone resorption (Papapanou \& Wennström, 1991; Papapanou et al., 1988; Persson, Rollender, Laurell, \& Persson, 1998). In Papapanou et al. (1988), the horizontal bone loss was recorded through the AC/CEJ measurement (after Bjorn, Hailing, and Thyberg 1969). Vertical bone loss was recorded as any morphological change seen as an oblique radiolucency $\geq 2 \mathrm{~mm}$ apically from the highest point of the AC, with signs of bone resorption. Similar techniques are still used in radiography to determine horizontal (Bahrami, Vaeth, Wenzel, \& Isidor, 2017) and vertical bone loss (Rams, Listgarten, \& Slots, 2018).

These clinical methods, including the concept of horizontal and vertical bone loss, have been adapted in human bioarchaeology when only the bones of the jaws and the teeth survive (Davies \& Picton, 1969; Davies, Picton, \& Alexander, 1969). In particular, the measurement between the CEJ and AC (after Russell 1956) proposed that AC levels of more or less than half the length of the root may indicate horizontal bone loss at different stages. The results are often averaged across the mouth to obtain a Tooth Cervical Height Index (TCH index). Initially, Davies et al. (1969) compared TCH index results to visual examination in the same individuals, concluding that a measurement $>2.5 \mathrm{~mm}$ suggests alveolar bone loss consistent with periodontal disease. This compares well with modern radiographic standards of $>3 \mathrm{~mm}$ (Bahrami et al., 2017) or $>1.9 \mathrm{~mm}$ (Hausmann, Allen, \& Clerehugh, 1991; Persson et al., 1998), but less than manual examination suggested in the WHO standard of $>3.5 \mathrm{~mm}$ (World-Health-Organization, 2013). The measurement of horizontal bone loss (AC/CEJ distance) has been taken up by many anthropologists and archaeologists (for example, Alexandersen, 1967; Eshed, Gopher, \& Hershkovitz, 2006; Lavigne \& Molto, 1995; Lukacs, 1989; Masotti et al., 2013; Meller et al., 2009). However, this empirical method of measurement, which appears to be an objective, repeatable, and straightforward approach, bears a fundamental problem when applied to skeletal remains. As demonstrated by Levers and Darling (1983), Murphy (1959), and Newman and Levers (1979), extensive occlusal wear can lead to the continuous eruption of a tooth to maintain an occlusal plane, extending CEJ/AC distance independently of alveolar resorption and periodontal disease. Davies and Picton (1969), two of the first to apply this method to archaeological remains, noted the impact of attrition on AC/CEJ distance; as attrition increased, so did the measurement. In a second paper, Davies and Picton (1969b) discuss the link between AC/CEJ distance and dental wear, while rarely referring to pathological change related to periodontal disease. Watson (1986) also demonstrated a clear correlation between increasing AC/CEJ distance and dental wear in Anglo Saxon to Tudor individuals. However, each of these papers referred to this process as 'alveolar recession' rather than the extension of the $\mathrm{AC} / \mathrm{CEJ}$ distance (due to continuous eruption). It may be the misunderstanding of this term that has led to the persistent of the use of the AC/CEJ measurement to record alveolar resorption connected to periodontal disease in skeletal remains. In archaeological collections - where dental wear is ubiquitous - measurement between the AC and CEJ is unreliable and unsuitable. Lavigne and Molto (1995, p. 269), cited by many as a basis for the technique, quite clearly stated that "the relationship of dental wear and over-eruption is not considered in the development of this system". For example, Eshed et al. (2006) noted a higher prevalence of horizontal bone loss in Natufian remains, interpreted as indicative of a higher prevalence of periodontal disease. However, high levels of dental wear were also recorded in this group, which is likely to have impacted the results and interpretations of the periodontal disease prevalence. It is unfortunate that, without the presence of soft tissue, this straightforward method, so useful in modern clinical research, cannot be applied to archaeological material due to the impact of dental wear. This is particularly true of ancient populations, where dental wear was almost ubiquitous.

Although tried and tested, measuring horizontal bone loss is not an appropriate approach in archaeological populations with high dental wear. However, observation of vertical bone loss has also been utilised in archaeology. This approach assesses morphological changes and the vertical loss of bone around the tooth root(s), thus recording changes in the contour (rather than height) of the interdental alveolar crest. Such changes are often recorded in clinical research (Hausmann et al., 1991; Papapanou et al., 1988; Persson et al., 1998; Rams et al., 2018), with perhaps the clearest definition made by Papapanou et al. (1988): any morphological change seen as an oblique radiolucency in a radiograph, extending apically beside the tooth root, from the highest point of the $\mathrm{AC}$, with signs of bone resorption. In archaeology, the most commonly used method for recording vertical bone loss was developed by Kerr (1988). Kerr recognised the fundamental problem of using the AC/CEJ distance in archaeological material, stating that such measurements "do not adequately observe the disease entity they purport to" (Kerr, 1986, p. 191). Kerr followed on from work started by Costa (1982), recording altered bone architecture, looking at infra-bony pockets and porosity (termed osteoporosis by Costa). Costa, however, had not accounted for the episodic nature of the disease, 
instead implying that it was progressive. In 1988, Kerr examined the Aberdeen Carmelite archaeological remains, drawing close parallels to histological changes seen in modern clinical sections of alveolar bone with periodontal disease at various stages. From this work, Kerr created the following interdental septum/alveolar crest) scores (adapted from Kerr 1988):

0. Unrecordable. Tooth on either side of the septum lost ante-mortem or the septum damaged postmortem

1. Septal form characteristic of its region (convex in incisor region, grading to flat in the molar region). The cortical surface is smooth and virtually uninterrupted by foramina, depressions or grooves.

2. Septal form characteristic of the region. Cortical surface showing a range of morphology, from many small foramina/shallow grooves to a cortical surface showing larger foramina and/or prominent grooves or ridges.

3. Septal form showing breakdown of contour with bone loss in the form of a shallow depression extending across the interspace from the buccal to lingual aspect, or as one or more smaller discrete areas of bone destruction, the essential and distinguishing features being a sharp and ragged texture to the bone.

4. Septal form showing breakdown of contour with bone loss similar to that seen in score 3 , the essential difference being the bone surface. Instead of being ragged in appearance, the bone has a porous or smooth honeycomb effect with all defects rounded.

5. Presence of deep infra-bony defect with sides sloping at 45 degrees or more and with a depth of $3 \mathrm{~mm}$ or more. The surface may be sharp and ragged or smooth and honeycombed.

Clinical measurements tend to focus on the periodontal pocket depth (Gingival margin/ AC) and attachment loss (CEJ/AC). In archaeological material, the absence of soft tissue (or, if present, highly altered) prevents an assessment of the pocket depth. In Kerr's system - although not a measurement - attachment loss is indicated in scores 3 to 5 , where the original architectural contour of the bone has been lost. Whether seen as a shallow change (score 3), a deep pocket (score 5), or a quiescent (healing) phase (score 4), this would 'clinically' be recorded as an attachment loss and measured by probing. Therefore, it may be possible to compare the prevalence of Kerr scores 3 to 5 with that of attachment loss - independent of the extent - recorded in modern clinical data. Comparing Kerr scores 3 to 5 with radiographic data poses a greater problem. Many papers mention the limitations of visually examining radio- graphs as they may only show demineralisation in bone once it has reached $30-50 \%$ or more (Page \& Eke, 2007; Research-Science-Therapy-Committee, 2003). Thus, subtle changes (i.e. Kerr Scores 2 or 3 ) may, perhaps, not easily be detected in radiographs; particularly the slight changes in vascularity proposed with gingivitis (see below). However, the recent use of subtraction imaging might compare well with Kerr's earlier stages, with demineralisations as low as 5\% being detected (Gröndahl \& Gröndahl, 1983). However, subtraction imaging techniques focus on treatment rather than diagnosis (Corbet, Ho, \& Lai, 2009; Page \& Eke, 2007; Research-ScienceTherapy-Committee, 2003) and do not include scores or stage-like evaluations, making like-for-like comparisons difficult. The higher Kerr scores, such as 4 or 5, indicate clearer vertical bone loss. Score 4 - the 'quiescent' phase - is likely to correspond to the periods of healing or reduced inflammation seen by Page and Schroeder (1976), reflecting the dynamic nature of periodontal disease. Radiographs published by Fish (1948, pp. 388, Figure 175), for example, show a case of Kerr scores 4 or 5 (dependent on depth - no scale given) with a deep angular defect with smooth edges visible on the radiograph.

Perhaps most controversially, Kerr (1988) argues that gingivitis may be recognised in the alveolar bone (Score 2). Prior to Kerr's work, and since its publication, researchers have suggested that the initial inflammation only effects the soft tissues and cannot be detected in archaeological material as it involves no loss of attachment (Page \& Schroeder, 1976; Schwartz et al., 1997). However, Kerr suggests that the porosity frequently seen in the alveolar crest (Costa, 1982; Kerr, 1986, 1988) reflects the increased vascularisation associated with gingival inflammation in gingivitis (Hajishengallis \& Korostoff, 2017; Page \& Schroeder, 1976). In chronic gingivitis, neutrophils have the ability to influence the bone remodelling process (Page \& Schroeder, 1976;

Schwartz et al., 1997); however, Schwartz et al. (1997) note that ultrastructural changes in bone do not occur in gingivitis - only as it progresses to periodontal disease. This is not supported by earlier research from Kennedy (1974), Hausmann, Ortman, and Sedransk (1979), and Heijl, Rifkin, and Zander (1976); and, the paper by Schwartz et al. (1997) may actually be referring to the structural resorption of bone and the loss of attachment, rather than remodelling to account for increased vascularity as Kerr has suggested. Indeed, Kennedy (1974) found that with gingivitis there was a significant increase in vascularity after only 2 weeks, including an increased number of vessels perforating the alveolar crest. Hausmann et al. (1979) supports this finding, revealing a decrease in alveolar bone mass using ${ }^{125 I}$ 
absorptiometry in cases of gingivitis in monkeys. Heijl et al. (1976) and Kennedy and Polson (1973)also found increases in osteoclast activity and bone loss and remodelling in cases of induced gingivitis.

While these studies support Kerr's idea, further clinical and radiological work may be required to clarify the impact of gingivitis on the alveolar crest. The subtle loss of bone density associated with the remodelling of the alveolar crest, when there is no attachment loss, is unlikely to be seen radiographically without the aid of subtraction imaging. Yet some histological studies support Kerr's findings. Fish (1948), in a comprehensive study of the surgical pathology of the mouth, showed that osteoclast activity had resorbed bone prior to any loss of attachment (Fish, 1948, pp. 317,331). Kronfeld (1933) also found that inflammation of the gingival tissue, with little to no attachment loss, was accompanied by some resorption of alveolar bone (Kronfeld, 1933, pp. 309, Figure 249). Kerr's (1988) method allows the recording of vertical bone loss in archaeological material. Though subjective, it is clearly defined and parallels clinical, radiographic, and histological understanding of both gingivitis and periodontal disease. It was developed to allow for detailed and meaningful comparisons between past and present prevalence of periodontal disease (Kerr, 1986), and thus was employed as the most appropriate method for recording periodontal disease in the current study.

\section{Methods}

Age and sex have been shown to affect the prevalence of periodontal disease and gingivitis (Amar \& Chung, 1994; Kinane, Podmore, \& Ebersole, 2001; Löe, 1965; Page \& Schroeder, 1976; Shiau \& Reynolds, 2010; Ziskin \& Nesse, 1946). In this study, age was recorded using the stages of pubic symphysis (Brooks \& Suchey, 1990) and auricular surface (Lovejoy etal., 1985) joint degeneration. Sex was recorded using sexually dimorphic features of the skull and pelvis, after Acsádi, Nemeskéri, and Balás (1970) (nuchal crest, mental eminence, glabella, orbital margin, mastoid process), Phenice (1969) (ventral arc, sub-pubic concavity, ischiopubic ramus ridge), Buikstra and Ubelaker (1994) (greater sciatic notch), and Rogers and Saunders (1994) (pubic body shape). The following categories were used:

Sex: Male; Male?; Undetermined; Female?; Female

Age: Adolescent $-<20$ years (with third molars in occlusion); Young Adult - 20-34 years; Middle Adult - 35-49 years; Old Adult - 50+ years; Adult - 20+ (age not assigned)

Pathological changes to the periodontium were recorded using the Kerr (1988) method described above, scoring vertical bone loss through changes in the texture and contour of the interdental alveolar crest. These changes were observed using a good light source and a 10x magnification hand-lens. An example of the changes associated with each of Kerr's scores can be seen in Figure 3. Results are divided into three alveolar regions: the anterior region comprising the alveolar crests between the left mesial canine and right mesial canine; the premolar region from the mesial first premolar to the mesial second premolar; and the molar region from the mesial first molar to mesial third molar. This approach records the distribution of pathological changes across the mouth and takes into account preservation bias (Antoine, 2017). Upper and lower dentitions were grouped together for the purpose of this study. Unobservable interdental septa were accounted for, allowing a true prevalence to be calculated for each group and the results are divided by age and sex (individuals assigned to the 'probable male' or 'probable female' categories were combined with those in the 'male' and 'female' categories respectively). The $95 \%$ confidence intervals were calculated, as well as the confidence interval of difference (CID), which shows a true statistical difference in prevalence when the confidence interval range does not pass through zero (Altman, 2000). Additionally, the more traditional Fisher's exact test (two-tailed) was used to provide a further test of statistical significance. A p-value of $<0.05$ was used to identify significant differences between groups.

Intra-observer error for Kerr's (1988) scoring method was tested on 60 interdental alveolar crests. These data were divided by score 0 (unobservable), score 1 (no pathological change), score 2 (porosity) and scores 3-5 (vertical bone loss). Table 3 shows the crosstabulation for the two intra-observations. Intraobservations matched in 53/60 instances. Cohen's k test showed good agreement between observations (according to Altman, 1999), with $\mathrm{k}=0.765$ and $\mathrm{p}=$ $<0.0005$, demonstrating significant agreement between observations. Table 4 shows the crosstabulation for the two inter-observations. Interobservations matched in 52/60 instances. Cohen's $\mathrm{K}$ test showed good agreement between observations (according to Altman, 1999), with $\mathrm{k}=0.800$ and $\mathrm{p}=$ $<0.0005$, demonstrating a significant agreement between observations.

The majority of error seen in the intra and interobservations were between scores 1 and 2, the difference between no pathological changes and increased porosity. The application of more light and better magnification was used to limit this error. However, this distinction is problematic. A minimal amount of porosity may be present in bone that has neither gin- 


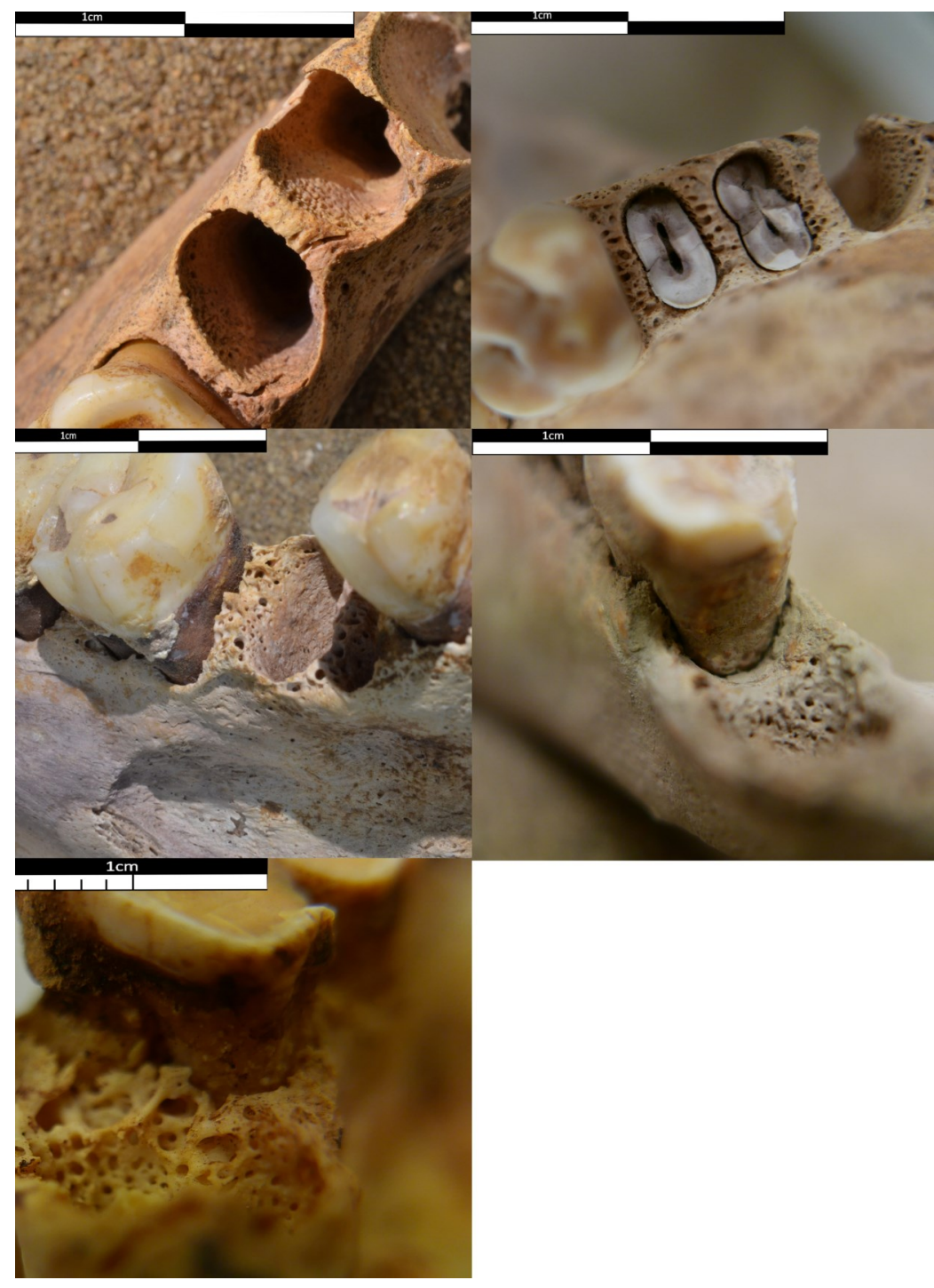

Figure 3. Examples of the different Kerr stages from the current study: Top left - Score 1 Septal form characteristic of its region with no pathological change; Top right - Score 2 Septal form characteristic of the region. Cortical surface showing a range of morphologies, from many small foramina/shallow grooves to a cortical surface showing larger foramina and/or prominent grooves or ridges; Middle left - Score 3 - Septal form showing breakdown of contour with bone loss in the form of a shallow depression extending across the interspace from the buccal to lingual aspect, or as one or more smaller discrete areas of bone destruction, the essential and distinguishing features being a sharp and ragged texture to the bone; Middle right - Score 4 Septal form showing breakdown of contour with bone loss similar to that seen in score 3, however, instead of being ragged in appearance, the bone has a porous or smooth honeycomb appearance; Bottom left - Score 5 Presence of deep infra-bony defect with sides sloping at 45 degrees or more and with a depth of $3 \mathrm{~mm}$ or more. The surface may be sharp and ragged or smooth. Photographs by R. Whiting, courtesy of the Trustees of The British Museum.

givitis nor periodontal disease (Berkovitz, Holland, \& Moxham, 1977, p. 191) and this limitation should be taken into account when interpreting results.

\section{Results}

Clear differences in the prevalence of Kerr scores 3-5 can be seen between the assemblages examined (Figure 4). Site R12 (Neolithic) has the lowest prevalence of all the sites in all tooth classes and for both sexes, as well as in its overall prevalence. The only exception is the anterior region of male jaws, which shows a Kerr score 3-5 prevalence of $0 \%$ of interdental alveolar crests (CI 0-18) at R12 and at H29 (CI 011). The Late Medieval site of 3-J-18 has the second lowest prevalence at 6.7\% (CI 4.6-9.7) for Kerr scores 3-5. Again, this is seen in all tooth classes, for both sexes, and overall (with the previous exception applying). Conversely, the Medieval site of 3-J-23 shows the highest prevalence in all tooth classes for both sexes and overall. The highest prevalence is that of the molar region of male individuals, with
47.5\% (CI 41.1-53.6) of all interdental alveolar bone showing pathological change consistent with Kerr scores 3-5. The prevalence at site $\mathrm{H} 29$ falls between those of the two Medieval sites.

Tables 5-10 demonstrate the statistically significant differences between all sites in all tooth regions, with only two exceptions. The interdental bone in the premolar region of sites $\mathrm{H} 29$ and 3-J-23 do not show a statistically significant difference. Here $16.2 \%$ (CI 12.1-22.7) and 20.2\% (CI 16.9-24) were recorded, respectively. The difference in prevalence between these sites is $3.5 \%$ (CID -9.5 to $3.4, \mathrm{P}=0.3300$ ). The interdental bone in the anterior region from sites R12 and 3-J-18 also show no significant difference. Here 0.0\% (CI 0.0-5.3) and 3.3\% (CI 2.3-4.6) were recorded, respectively. The difference in prevalence between these sites is $3.3 \%$ (CID -4.6 to $2.1 \mathrm{P}=0.2617$ ).

\section{Distribution comparison}

In both male and female individuals, as well as overall, each site shows a similar distribution of Kerr 


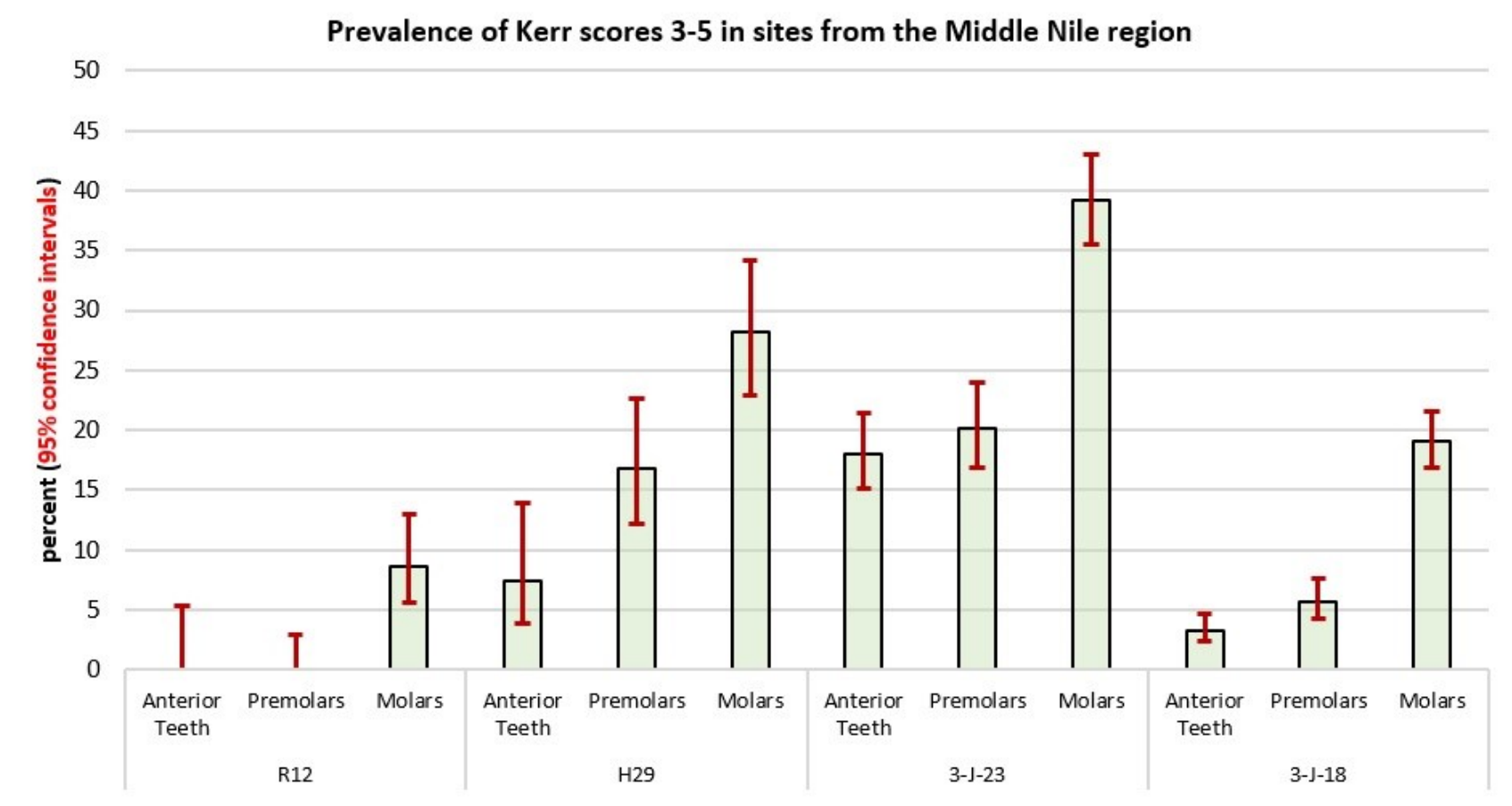

Figure 4: Box and whisker plot showing the prevalence of periodontal disease at sites R12, H29, 3-J-23 and 3J-18. Box plot indicates prevalence in each tooth region. Whiskers indicate the confidence intervals for each group based on the calculations set out in Altman, Machin, Bryant, and Gardner (2000, p. 47).

Table 3. Crosstabulation for intra-observer error for observations of Kerr scores. Numbers indicate counts of the Kerr Scores allocated in observation \#1 and \#2.

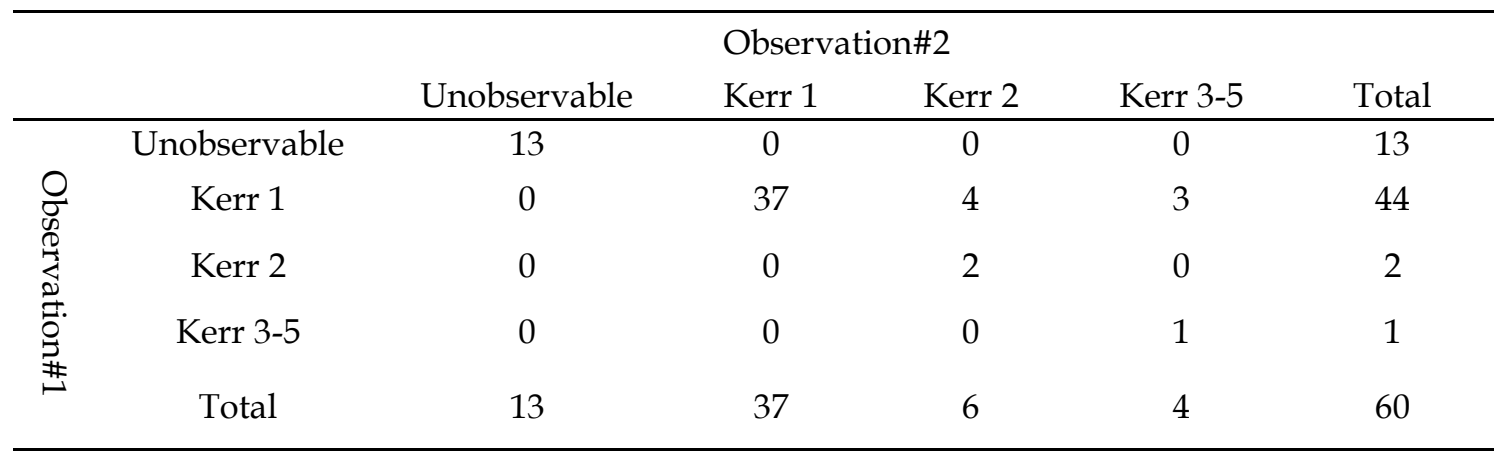

Table 4. Crosstabulation for inter-observer error observations for periodontal disease recording. Numbers indicate counts of the Kerr Scores allocated by observer \#1 and \#2.

\begin{tabular}{|c|c|c|c|c|c|c|}
\hline & \multicolumn{6}{|c|}{ Observer\#2 } \\
\hline & & Unobservable & Kerr 1 & Kerr 2 & Kerr 3-5 & Total \\
\hline \multirow{5}{*}{$\begin{array}{l}0 \\
\stackrel{0}{\infty} \\
0 \\
0 \\
0 \\
0 \\
\# \\
\#\end{array}$} & Unobservable & 6 & 0 & 0 & 1 & 7 \\
\hline & Kerr 1 & 0 & 24 & 3 & 0 & 27 \\
\hline & Kerr 2 & 0 & 3 & 16 & 0 & 19 \\
\hline & Kerr 3-5 & 0 & 0 & 1 & 6 & 7 \\
\hline & Total & 6 & 27 & 20 & 7 & 60 \\
\hline
\end{tabular}


Table 5: Site comparisons between R12 and H29 for Kerr scores 3-5 in each tooth region, as well as overall. Raw data, Confidence interval of difference (Altman et al., 2000) and P-value for two-tailed Fisher's exact test are shown. Significant values are shown in bold.

\begin{tabular}{|c|c|c|c|c|}
\hline R12/H29 & Anterior teeth & Premolars & Molars & Total \\
\hline \multirow{2}{*}{ Raw Data } & $0 / 68(0.0 \%)$ & $0 / 128(0.0 \%)$ & $20 / 232(8.6 \%)$ & $20 / 428(4.7 \%)$ \\
\hline & $8 / 108(7.4 \%)$ & $32 / 191(16.7 \%)$ & $68 / 241(28.2 \%)$ & $108 / 540(20 \%)$ \\
\hline CID & $-13.9(-7.4)-1.0$ & $-22.7(-16.8)-11.3$ & $-26.3(-19.6)-12.8$ & $-19.3(-15.3)-11.3$ \\
\hline Fisher's exact test & $P=0.0239$ & $P=<0.00001$ & $P=<0.00001$ & $P=<0.00001$ \\
\hline
\end{tabular}

Table 6: Site comparisons between R12 and 3-J-23 for Kerr scores 3-5 in each tooth region, as well as overall. Raw data, Confidence interval of difference (Altman et al., 2000) and P-value for two-tailed Fisher's exact test are shown. Significant values are shown in bold.

\begin{tabular}{ccccc}
\hline R12/3-J-23 & Anterior teeth & Premolars & Molars & Total \\
\hline \multirow{2}{*}{ Raw Data } & $0 / 68(0.0 \%)$ & $0 / 128(0.0 \%)$ & $20 / 232(8.6 \%)$ & $20 / 428(4.7 \%)$ \\
CID & $101 / 559(18 \%)$ & $97 / 480(20.2 \%)$ & $251 / 640(39.2 \%)$ & $449 / 1679(26.7 \%)$ \\
Fisher's exact test & $\mathbf{- 2 1 . 5 ( - 1 8 . 1 )} \mathbf{- 1 2 . 0}$ & $\mathbf{- 2 4 . 0} \mathbf{( - 2 0 . 2 )}-\mathbf{1 5 . 8}$ & $\mathbf{- 3 5 . 5 ( - 3 0 . 6 ) - 2 4 . 9}$ & $\mathbf{- 2 4 . 8} \mathbf{( - 2 2 . 1 )} \mathbf{- 1 8 . 9}$ \\
\hline
\end{tabular}

Table 7: Site comparisons between R12 and 3-J-18 for Kerr scores 3-5 in each tooth region, as well as overall. Raw data, Confidence interval of difference (Altman et al., 2000) and P-value for two-tailed Fisher's exact test are shown. Significant values are shown in bold.

\begin{tabular}{ccccc}
\hline R12/3-J-18 & Anterior teeth & Premolars & Molars & Total \\
\hline Raw Data & $0 / 68(0.0 \%)$ & $0 / 128(0.0 \%)$ & $20 / 232(8.6 \%)$ & $20 / 428(4.7 \%)$ \\
CID & $31 / 939(3.3 \%)$ & $45 / 788(6 \%)$ & $203 / 1063(19 \%)$ & $279 / 2790(10 \%)$ \\
Fisher's exact test & $-4.6(-3.3) 2.1$ & $\mathbf{- 7 . 6}(\mathbf{- 5 . 7 0 - 2 . 5}$ & $\mathbf{- 1 4 . 3 ( - \mathbf { 1 0 . 5 } ) \mathbf { 5 . 6 }}$ & $\mathbf{- 7 . 3 ( - 5 . 3 ) - \mathbf { 2 . 7 }}$ \\
\hline
\end{tabular}

Table 8: Site comparisons between H29 and 3-J-23 for Kerr scores 3-5 in each tooth region, as well as overall. Raw data, Confidence interval of difference (Altman et al., 2000) and P-value for two-tailed Fisher's exact test are shown. Significant values are shown in bold.

\begin{tabular}{|c|c|c|c|c|}
\hline H29/3-J-23 & Anterior teeth & Premolars & Molars & Total \\
\hline \multirow{2}{*}{ Raw Data } & $8 / 108(7.4 \%)$ & $32 / 191(16.7 \%)$ & $68 / 241(28.2 \%)$ & $108 / 540(20 \%)$ \\
\hline & $101 / 559(18 \%)$ & $97 / 480(20.2 \%)$ & $251 / 640(39.2 \%)$ & $449 / 1679(26.7 \%)$ \\
\hline CID & $-15.6(-10.7)-3.5$ & $-9.5(-3.5) 3.4$ & $-17.6(-11.0)-4.0$ & $-10.9(-6.7)-2.6$ \\
\hline Fisher's exact test & $P=0.0044$ & $P=0.3300$ & $P=0.0028$ & $P=0.0017$ \\
\hline
\end{tabular}

Table 9: Site comparisons between H29 and 3-J-18 for Kerr scores 3-5 in each tooth region, as well as overall. Raw data, Confidence interval of difference (Altman et al., 2000) and P-value for two-tailed Fisher's exact test are shown. Significant values are shown in bold.

\begin{tabular}{|c|c|c|c|c|}
\hline H29/3-J-18 & Anterior teeth & Premolars & Molars & Total \\
\hline \multirow{2}{*}{ Raw Data } & $8 / 108(7.4 \%)$ & $32 / 191(16.7 \%)$ & $68 / 241(28.2 \%)$ & $108 / 540(20 \%)$ \\
\hline & $31 / 939(3.3 \%)$ & $45 / 788(6 \%)$ & $203 / 1063(19 \%)$ & $279 / 2790(10 \%)$ \\
\hline CID & $0.3(4.1) 10.7$ & $6.1(11.0) 17.1$ & 3.3 (9.1) 15.5 & $6.6(10.0) 13.7$ \\
\hline Fisher's exact test & $P=0.0529$ & $P=<0.0001$ & $P=0.0021$ & $\mathrm{P}=<0.0001$ \\
\hline
\end{tabular}


Table 10: Site comparisons between 3-J-23 and 3-J-18 for Kerr scores 3-5 in each tooth region, as well as overall. Raw data, Confidence interval of difference (Altman et al., 2000) and P-value for two-tailed Fisher's exact test are shown. Significant values are shown in bold.

\begin{tabular}{ccccc}
\hline 3-J-23/3-J-18 & Anterior teeth & Premolars & Molars & Total \\
\hline \multirow{2}{*}{ Raw Data } & $101 / 559(18 \%)$ & $97 / 480(10.2 \%)$ & $251 / 640(39.2 \%)$ & $449 / 1679(26.7 \%)$ \\
& $31 / 939(3.3 \%)$ & $45 / 788(6 \%)$ & $203 / 1063(19 \%)$ & $279 / 2790(10 \%)$ \\
CID & $\mathbf{1 1 . 5 ( 1 4 . 8 ) \mathbf { 1 8 . 3 }}$ & $\mathbf{1 0 . 7}(\mathbf{1 4 . 5 )} \mathbf{1 8 . 6}$ & $\mathbf{1 5 . 7} \mathbf{( 2 0 . 1 ) \mathbf { 2 4 . 6 }}$ & $\mathbf{1 4 . 4} \mathbf{( 1 6 . 7 ) \mathbf { 1 9 . 2 }}$ \\
Fisher's exact test & $\mathbf{P}=\mathbf{0 . 0 0 0 0 1}$ & $\mathbf{P}=<\mathbf{0 . 0 0 0 0 1}$ & $\mathbf{P}=<\mathbf{0 . 0 0 0 0 1}$ & $\mathbf{P}=<\mathbf{0 . 0 0 0 0 1}$ \\
\hline
\end{tabular}

scores 3-5. The anterior region of the jaws has the lowest prevalence, followed by the premolar region, with the molar region displaying the highest prevalence in every site. In male individuals from both Medieval sites (3-J-18 and 3-J-23), a similar prevalence is present in the anterior and premolar regions. Overall, the premolars from site $3-\mathrm{J}-23$ show a $4.8 \%$ higher prevalence than the anterior region (CID -13.5 to $3.7, \mathrm{P}=0.2966$ ), while at site $3-\mathrm{J}-18$, there is a difference of $0.6 \%$ between the tooth regions (CID -4.6 to $3.2, \mathrm{P}=0.7684)$. In contrast, there is a statistically significant difference in prevalence between the anterior and premolar regions in the males from site $\mathrm{H} 29$ $15 \%$ (CID -26.1 to $-2.0, \mathrm{P}=0.0254$ ). The difference in prevalence between the anterior and premolar regions at all three sites is less pronounced in female individuals (Figure 5). At R12, Kerr scores 3-5 are only found in the molar region, this was true of both sexes and in overall prevalence.

Comparisons of age and sex

Figure 5 shows the prevalence of Kerr Scores 3-5 in each of the groups examined, divided by age and sex. In nearly every tooth region of each assemblage, the middle adult category shows a higher prevalence of Kerr Scores 3-5 than the young adults- with the exception of the premolar region at $\mathrm{H} 29$ where young adult males show a slightly higher prevalence than middle adult males. However, not all these differences are statistically significant (Tables 11-18). In fact, in the earlier periods, the Neolithic and Kerma groups show no statistical significance between age categories for either sex. Yet, in the Medieval groups, middle adults show a statistically higher prevalence than young adults in every tooth region for male individuals. However, this is not the case for female individuals, where a statistical difference between age categories is only seen in the molar region at 3-J18 , and in the molars and premolars at 3-J-23. In addition, middle adult males, at both Medieval sites, show a significantly higher prevalence of Kerr Scores 3-5 than middle adult females in the anterior dentition.

\section{Discussion}

The sites examined in this study reveal a wide range in the prevalence of Kerr scores 3 to 5 (from $4.7 \%$ at R12 to $26 \%$ at 3-J-23), which represents destructive bone loss relating to periodontal disease (Kerr, 1988). In modern populations from across the globe, P. E. Petersen (2003) reports periodontal disease ranging from 5 to $15 \%$. Petersen's data, however, only include individuals with periodontal pockets $\geq 6 \mathrm{~mm}$, and cannot be directly compared with the higher prevalence rates reported here as the latter include a greater range of periodontal remodelling. The current study also differs in that it records changes per interdental septum rather than per individual. It should be noted that due to varying levels of preservation, the numbers of individuals with age-at-death and sex estimates were small at sites R12 and H29, but relatively large at the two Medieval sites. The results from these earlier sites are thus less likely to be as representative as those from the later sites.

The Neolithic site of R12 shows the lowest prevalence of periodontal disease in all tooth regions and overall for males, females, and both age categories. Periodontal disease is only present in the molar region, with none observed in the anterior or premolar teeth. Prevalence at H29 is higher than that of R12, with pathological changes found in all regions of the dentition. Site 3-J-23 has considerably higher prevalence rates than both R12 and H29. However, at the later Medieval site of 3-J-18, prevalence rates are lower than those at both the earlier Medieval and Kerma Ancien sites. Current understanding of the biological processes contributing to periodontal disease suggest that a range of factors can contribute to the initiation and progression of the condition. Its association with systemic inflammation is particularly relevant here (Barnett, 2006; Page, 1998; P. E. Petersen et al., 2005; Thoden van Velzen, AbrahamInpijn, \& Moorer, 1984), with greater inflammation in the body causing susceptibility to the hypersensitive response involved in periodontal disease and vice versa. The archaeological record suggests that during the Neolithic period, settlement may have been more temporary and communities more mobile, in part due to the more humid environment and 


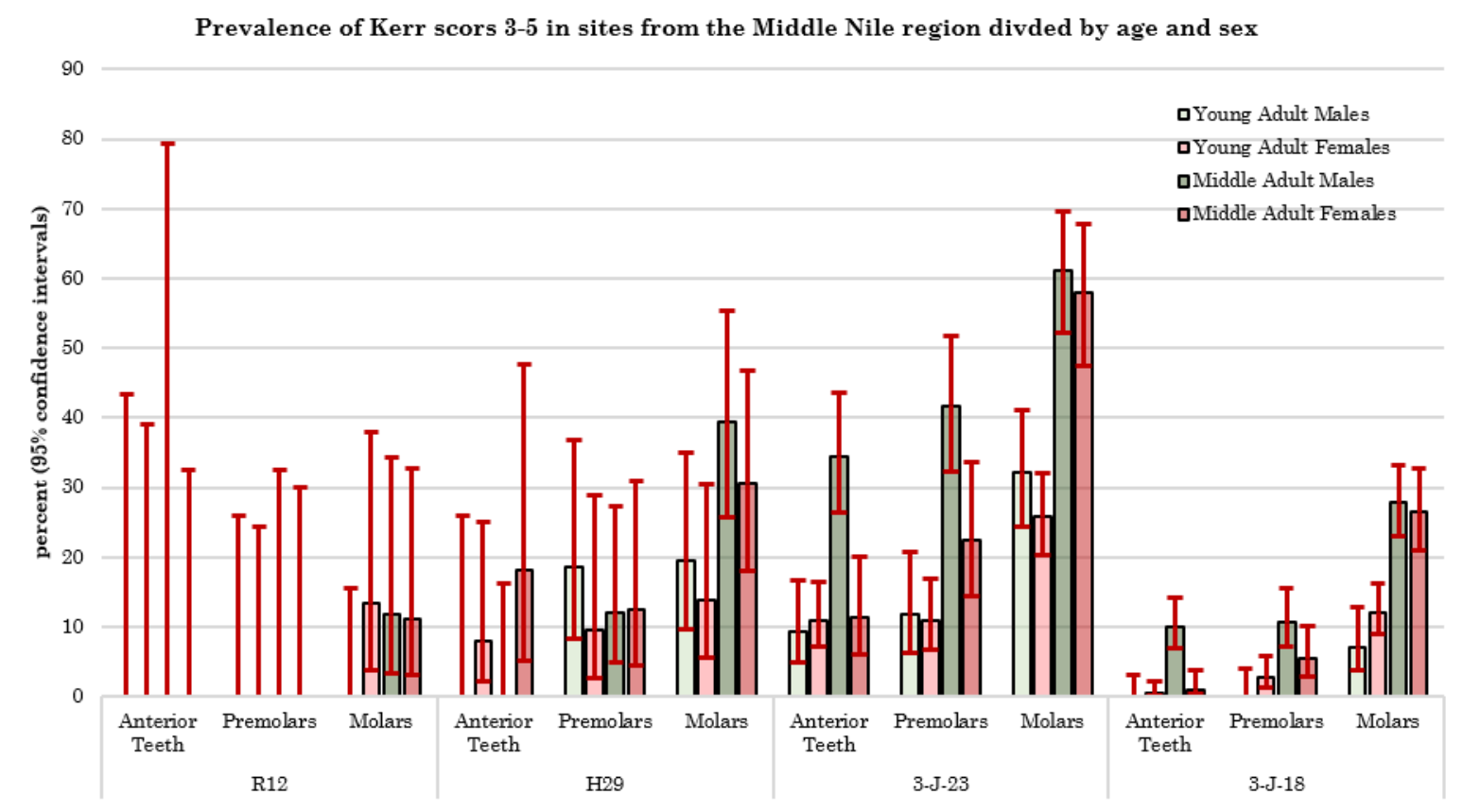

Figure 5. Box and whisker plot showing the prevalence of periodontal disease at sites R12, H29, 3-J23 and 3-J-18. Box plot indicates prevalence in each tooth region, for young and middle adult males and females. Whiskers indicate the confidence intervals for each group based on the calculations set out in Altman et al. (2000, p. 47).

Table 11: Comparisons between young and middle adult males at R12 for Kerr scores 3-5 in each tooth region, as well as overall. Raw data, Confidence interval of difference (Altman et al., 2000) and P-value for two-tailed Fisher's exact test are shown. Significant values are shown in bold.

\begin{tabular}{lccccc}
\hline & R12 Males & Anterior teeth & Premolars & Molars & Total \\
\hline \multirow{2}{*}{ Raw Data } & (Young adults) & $0 / 5(0.0 \%)$ & $0 / 11(0.0 \%)$ & $0 / 21(0.0 \%)$ & $0 / 37(0.0 \%)$ \\
& (Middle adults) & $0 / 1(0.0 \%)$ & $0 / 8(0.0 \%)$ & $2 / 17(11.8 \%)$ & $2 / 26(7.7 \%)$ \\
CID & & $-79.3(0.0 \%) 43.4$ & $-32.4(0.0) 25.9$ & $-34.3(-11.8) 5.9$ & $-24.1(-7.7) 3.2$ \\
Fisher's exact test & & $\mathrm{P}=1$ & $\mathrm{P}=1$ & $\mathrm{P}=0.19$ & $\mathrm{P}=0.16$ \\
\hline
\end{tabular}

Table 12: Comparisons between young and middle adult females at R12 for Kerr scores 3-5 in each tooth region, as well as overall. Raw data, Confidence interval of difference (Altman et al., 2000) and P-value for two-tailed Fisher's exact test are shown. Significant values are shown in bold.

\begin{tabular}{lccccc}
\hline & \multicolumn{1}{c}{ R12 Females } & Anterior teeth & Premolars & Molars & Total \\
\hline \multirow{2}{*}{ Raw Data } & (Young adults) & $0 / 6(0.0 \%)$ & $0 / 12(0.0 \%)$ & $2 / 15(13.5 \%)$ & $2 / 33(6.0 \%)$ \\
& (Middle adults) & $0 / 8(0.0 \%)$ & $0 / 9(0.0 \%)$ & $2 / 18(11.1 \%)$ & $2 / 35(5.7 \%)$ \\
CID & & $-32.4(0.0) 39.0$ & $-32.4(0.0) 24.3$ & $-21.5(2.2) 28.0$ & $-13.3(0.3) 14.5$ \\
Fisher's exact test & & $\mathrm{P}=1$ & $\mathrm{P}=1$ & $\mathrm{P}=1$ & $\mathrm{P}=1$ \\
\hline
\end{tabular}


Table 13: Comparisons between young and middle adult males at H29 for Kerr scores 3-5 in each tooth region, as well as overall. Raw data, Confidence interval of difference (Altman et al., 2000) and P-value for two-tailed Fisher's exact test are shown. Significant values are shown in bold.

\begin{tabular}{lccccc}
\hline & H29 Males & Anterior teeth & Premolars & Molars & Total \\
\hline \multirow{2}{*}{ Raw Data } & (Young adults) & $0 / 11(0.0 \%)$ & $5 / 27(18.5 \%)$ & $7 / 36(19.4 \%)$ & $12 / 74(16.2 \%)$ \\
& (Middle adults) & $0 / 20(0.0 \%)$ & $4 / 33(12.1 \%)$ & $15 / 38(39.5 \%)$ & $19 / 91(20.9 \%)$ \\
CID & & $-16.1(0.0) 25.9$ & $-12.0(6.4) 26.0$ & $-38.6(-20.0) 0.8$ & $-16.2(-4.7) 7.6$ \\
Fisher's exact test & & $\mathrm{P}=1$ & $\mathrm{P}=0.71$ & $\mathrm{P}=0.07$ & $\mathrm{P}=0.54$ \\
\hline
\end{tabular}

Table 14: Comparisons between young and middle adult females at H29 for Kerr scores 3-5 in each tooth region, as well as overall. Raw data, Confidence interval of difference (Altman et al., 2000) and P-value for two-tailed Fisher's exact test are shown. Significant values are shown in bold.

\begin{tabular}{lccccc}
\hline & H29 Females & Anterior teeth & Premolars & Molars & Total \\
\hline \multirow{2}{*}{ Raw Data } & (Young adults) & $2 / 25(8.0 \%)$ & $2 / 21(9.5 \%)$ & $4 / 29(13.8 \%)$ & $8 / 75(10.6 \%)$ \\
& (Middle adults) & $2 / 11(18.2 \%)$ & $3 / 24(12.5 \%)$ & $11 / 36(30.6 \%)$ & $16 / 71(22.5 \%)$ \\
CID & & $-40.3(-10.2) 11.2$ & $22.3(-3.0) 18.1$ & $-35.1(-16,8) 4.2$ & $-24.0(-11.9) 0.3$ \\
Fisher's exact test & & $\mathrm{P}=0.57$ & $\mathrm{P}=1$ & $\mathrm{P}=0.14$ & $\mathrm{P}=0.07$ \\
\hline
\end{tabular}

Table 15: Comparisons between young and middle adult males at 3-J-23 for Kerr scores 3-5 in each tooth region, as well as overall. Raw data, Confidence interval of difference (Altman et al., 2000) and P-value for two-tailed Fisher's exact test are shown. Significant values are shown in bold.

\begin{tabular}{lccccc}
\hline & 3-J-23 Males & Anterior teeth & Premolars & Molars & Total \\
\hline \multirow{2}{*}{ Raw Data } & (Young adults) & $9 / 97(9.3 \%)$ & $9 / 77(11.7 \%)$ & $37 / 115(32.2 \%)$ & $55 / 289(19.0 \%)$ \\
& (Middle adults) & $40 / 116(34.5 \%)$ & $40 / 96(41.7 \%)$ & $71 / 116(61.2 \%)$ & $151 / 328(46.0 \%)$ \\
CID & & $\mathbf{- 3 5 . 2 ( - 2 5 . 2 )} \mathbf{- 1 4 . 3}$ & $\mathbf{- 4 1 . 3 ( - 3 0 . 0 ) - 1 7 . 0}$ & $\mathbf{- 4 2 . 1} \mathbf{( - 3 0 . 8 )} \mathbf{- 1 8 . 0}$ & $\mathbf{- 3 3 . 8}(\mathbf{- 2 7 . 0 )} \mathbf{- 1 9 . 8}$ \\
Fisher's exact test & $\mathbf{P = < 0 . 0 0 0 1}$ & $\mathbf{P}=<\mathbf{0 . 0 0 0 1}$ & $\mathbf{P = < 0 . 0 0 0 1}$ & $\mathbf{P = < 0 . 0 0 0 1}$ \\
\hline
\end{tabular}

Table 16: Comparisons between young and middle adult females at 3-J-23 for Kerr scores 3-5 in each tooth region, as well as overall. Raw data, Confidence interval of difference (Altman et al., 2000) and P-value for two-tailed Fisher's exact test are shown. Significant values are shown in bold.

\begin{tabular}{|c|c|c|c|c|c|}
\hline \multicolumn{2}{|c|}{ 3-J-23 Females } & Anterior teeth & Premolars & Molars & Total \\
\hline \multirow{2}{*}{ Raw Data } & (Young adults) & $20 / 182(11.0 \%)$ & $16 / 148(10.8 \%)$ & $53 / 206(25.7 \%)$ & $89 / 536(16.6 \%)$ \\
\hline & (Middle adults) & 9/80 (11.3\%) & $16 / 71(22.5 \%)$ & $51 / 88(58.0 \%)$ & $76 / 239(31.7 \%)$ \\
\hline \multicolumn{2}{|l|}{ CID } & $-9.8(-0.3) 7.2$ & $-23.4(-11.7)-1.6$ & $-43.4(-32.2)-20.0$ & $-22.0(-15.2)-8.7$ \\
\hline \multicolumn{2}{|c|}{ Fisher's exact test } & $\mathrm{P}=1$ & $P=0.02$ & $\mathrm{P}=<0.0001$ & $\mathrm{P}=<0.0001$ \\
\hline
\end{tabular}

Table 17: Comparisons between young and middle adult males at 3-J-18 for Kerr scores 3-5 in each tooth region, as well as overall. Raw data, Confidence interval of difference (Altman et al., 2000) and P-value for two-tailed Fisher's exact test are shown. Significant values are shown in bold.

\begin{tabular}{lccccc}
\hline & 3-J-18 Males & Anterior teeth & Premolars & Molars & Total \\
\hline \multirow{2}{*}{ Raw Data } & (Young adults) & $0 / 118(0.0 \%)$ & $0 / 91(0.0 \%)$ & $9 / 127(7.1 \%)$ & $9 / 336(2.6 \%)$ \\
& (Middle adults) & $26 / 260(10.0 \%)$ & $23 / 216(10.6 \%)$ & $81 / 291(27.8 \%)$ & $130 / 767(16.9 \%)$ \\
CID & & $\mathbf{- 1 4 . 2}(\mathbf{- 1 0 . 0 )}-\mathbf{5 . 6}$ & $\mathbf{- 1 5 . 5 ( - \mathbf { 1 0 . 6 ) } - \mathbf { 5 . 3 }}$ & $\mathbf{- 2 7 . 1}(\mathbf{- 2 0 . 7 )} \mathbf{- 1 3 . 2}$ & $\mathbf{- 4 7 . 9}(\mathbf{- 4 2 . 0 )} \mathbf{- 3 5 . 9}$ \\
Fisher's exact test & & $\mathbf{P}=<\mathbf{0 . 0 0 0 1}$ & $\mathbf{P}=\mathbf{0 . 0 0 0 5}$ & $\mathbf{P}=<\mathbf{0 . 0 0 0 1}$ & $\mathbf{P}=<\mathbf{0 . 0 0 0 1}$ \\
\hline
\end{tabular}


Table 18: Comparisons between young and middle adult females at 3-J-18 for Kerr scores 3-5 in each tooth region, as well as overall. Raw data, Confidence interval of difference (Altman et al., 2000) and P-value for two-tailed Fisher's exact test are shown. Significant values are shown in bold.

\begin{tabular}{lccccc}
\hline & 3-J-18 Females & Anterior teeth & Premolars & Molars & Total \\
\hline \multirow{2}{*}{ Raw Data } & (Young adults) & $1 / 266(0.4 \%)$ & $6 / 222(2.75)$ & $37 / 306(12.1 \%)$ & $44 / 794(5.5 \%)$ \\
& (Middle adults) & $2 / 191(1.0 \%)$ & $9 / 165(5.5 \%)$ & $57 / 216(26.4 \%)$ & $68 / 572(11.8 \%)$ \\
CID & & $-2.1(-0.3) 1.5$ & $-7.6(-2.8) 1.2$ & $\mathbf{- 2 1 . 3 ( - 1 4 . 3 ) ~ - 7 . 5}$ & $\mathbf{- 9 . 6}(-\mathbf{6 . 3}) \mathbf{- 3 . 3}$ \\
Fisher's exact test & & $\mathrm{P}=0.57$ & $\mathrm{P}=0.18$ & $\mathbf{P = < 0 . 0 0 0 1}$ & $\mathbf{P = < 0 . 0 0 0 1}$ \\
\hline
\end{tabular}

Table 19: Comparison of the male, female and overall Kerr scores 3-5 recorded in this study with Wasterlain et al. (2011) and Kerr (1991). Raw data and prevalence (\%) are provided.

\begin{tabular}{cccc}
\hline Site/Study & Male & Female & Overall \\
\hline \multirow{2}{*}{ R12 } & $7 / 141$ & $4 / 108$ & $20 / 428$ \\
& $(5 \%)$ & $(3.7 \%)$ & $(4.7 \%)$ \\
H29 & $31 / 165$ & $45 / 246$ & $108 / 540$ \\
& $(18.7 \%)$ & $(18.7 \%)$ & $(20 \%)$ \\
3-J-23 & $214 / 639$ & $165 / 779$ & $449 / 1679$ \\
& $(33.4 \%)$ & $(21.1 \%)$ & $(26.7 \%)$ \\
3-J-18 & $140 / 1129$ & $119 / 1432$ & $279 / 2790$ \\
& $(12.4 \%)$ & $(8.3 \%)$ & $(10 \%)$ \\
Wasterlain et al. (2011) & $773 / 4980$ & $602 / 4420$ & $1335 / 9400$ \\
& $(14.7 \%)$ & $(13.6 \%)$ & $(14.2 \%)$ \\
Kerr (1991) & - & - & $702 / 3142$ \\
& & & $(22.3 \%)$ \\
\hline
\end{tabular}

Table 20: Comparison of Kerr scores 3-5 in this study and Kerr (1991). Raw data and prevalence (\%) provided by dental distribution

\begin{tabular}{ccccc}
\hline & Anterior teeth & Premolars & Molars & Total \\
\hline \multirow{2}{*}{ R12 } & $0 / 68$ & $0 / 128$ & $20 / 232$ & $20 / 428$ \\
& $(0.0 \%)$ & $(0.0 \%)$ & $(8.6 \%)$ & $(4.7 \%)$ \\
H29 & $8 / 108$ & $32 / 191$ & $68 / 241$ & $108 / 540$ \\
& $(7.4 \%)$ & $(16.7 \%)$ & $(28.2 \%)$ & $(20 \%)$ \\
$3-J-23$ & $101 / 559$ & $97 / 480$ & $251 / 640$ & $449 / 1679$ \\
& $(18 \%)$ & $(20.2 \%)$ & $(39.2 \%)$ & $(26.7 \%)$ \\
$3-J-18$ & $31 / 939$ & $45 / 788$ & $203 / 1063$ & $279 / 2790$ \\
& $(3.3 \%)$ & $(6 \%)$ & $(19 \%)$ & $(10 \%)$ \\
Kerr (1991) & $184 / 1041$ & $171 / 1047$ & $335 / 1339$ & $702 / 3142$ \\
& $(17.6 \%)$ & $(16.3 \%)$ & $(26.5 \%)$ & $(22.3 \%)$ \\
\hline
\end{tabular}

a reliance on pastoral cultural practices (Bard, 2008;

Gautier \& Van Neer, 2011; Hassan, 1986; L.

Krzyżaniak, 2004; Wengrow et al., 2014). At this time, population clusters may have been smaller and may have had less contact with other groups, limiting the spread of disease and systemic inflammation. This may in part explain the very low levels of periodontal disease prevalence in the Neolithic Group and the much higher levels in the later groups, particularly the Medieval site of 3-J-23. Unfortunately, none of the cemeteries examined in this study had associated settlements and occupation size or pat- terns could not be established.

Genetic susceptibility is also likely to affect the prevalence of periodontal disease (Hajishengallis \& Korostoff, 2017; Kornman \& di Giovine, 1998; Kornman et al., 1997; Laine, Crielaard, \& Loos, 2012; Page \& Schroeder, 1976). Clinical studies have demonstrated that certain gene expressions influence patient susceptibility to both aggressive and chronic periodontal disease (Kornman \& di Giovine, 1998; Laine et al., 2012; Offenbacher, Barros, \& Beck, 2008). In the Nile Valley, Elamin, Skaug, Ali, Bakken, and Albandar (2010) study of the periodontal status of 
Sudanese students concludes that African ethnicity and male sex are risk factors in young people aged 13-19 years. If individuals from Site R12 had a very different genetic make-up to the other sites examined, this may explain some of the very different prevalence rates observed here. However, no aDNA studies have been made. The work by Irish (2008), using dental morphology as a proxy to genetics, suggests a close biological affinity between R12 and other Nubian groups of the time, as well as with groups from subsequent periods. However, dental morphological data is not currently available for $\mathrm{H} 29$ or the Fourth Cataract sites.

Few clinical studies have linked periodontal disease to diet (Björnsson et al., 2003; Person, 1961; Watson, 1994). In Sudan, the archaeological record suggests an agricultural transition or intensification between the Neolithic and Medieval periods

(Björnsson et al., 2003; Chaix, 1984, 2007; Clapham \& Rowley-Conwy, 2007; Fuller, 2004; Fuller \& Edwards, 2001; Iacumin et al., 1961; Watson, 1994). An increase in consumption of grains during this period may have affected the make-up of the oral flora within the supra-gingival biofilm and, in turn, susceptibility to periodontal disease.

When compared to Wasterlain, Cunha, and Hillson (2011), which also used the Kerr method on individuals of known age and sex from the Coimbra collection in Portugal, the overall prevalence for the Coimbra post-industrial group (14.2\%; CI 13.5-14.9) falls between that of the later Medieval group from 3 -J-18 (10\%; CI 8.9-11.2) and the Kerma Ancien group from H29 (20\%;CI 16.8-23.6). The Coimbra data also has a significantly higher prevalence than that of 3-J18 (4.2\%; CID -5.5 to $-2.8 \mathrm{P}=<0.00001)$, as well as a significantly lower prevalence than $\mathrm{H} 29$ (5.8\%; CID 2.6 to $9.4 \mathrm{P}=0.0003$ ). The Coimbra data also have a statistically lower prevalence than 3-J-23 and a higher prevalence than R12. The results could not be directly compared to the Medieval Scottish collections (AD 900-1600) examined by Kerr (1991; see Table 19) due to its inclusion of sub adults. However, once Kerr's data is adjusted to exclude the sub-adults (Table 19), periodontal disease was observed in $22.3 \%$ of interdental alveolar crests. This is $2.3 \%$ higher than the prevalence observed at H29 (CID 1.5 to $5.8 \mathrm{P}=0.2378$ ) and significantly higher than results from sites R12 (17.7\%; CID 14.9 to 19.9

$\mathrm{P}=<0.00001)$ and 3-J-18 (12.3\%; CID 10.5 to 14.2 $\mathrm{P}=<0.00001)$, as well as significantly lower than 3-J23. The Middle Nile Valley data compares well with the range seen in other collections with the exception of R12, where prevalence is much lower than all other collections, and even lower than the range observed in modern populations (Petersen, 2003).

The Medieval Scottish data by Kerr (1991) also show a prevalence of periodontal disease of $17.6 \%$ (CI 15.5-20.1) in the anterior region, 16.3\% (CI 14.218.7) in the premolar region, and $26.5 \%$ (CI 24.2-28.9) in the molar region (Table 20). Prevalence rates in the premolar and molar regions are comparable with those found at site H29. However, the prevalence recorded in the anterior region was significantly higher than $\mathrm{H} 29$ (10.3\%; CID -14.6 to $-3.4 \mathrm{P}=0.0044)$ and aligns more closely with that of 3-J-23. A similar distribution of periodontal disease across the mouth was found at Coimbra and the Sudanese sites, with a higher prevalence in the molar region and the lowest prevalence in the anterior region.

Some studies have found a close link between periodontal disease and dental hygiene (Axelsson \& Lindhe, 1981; Löe, 2000; P. E. Petersen et al., 2005). In modern Sudan, Darout, Albandar, and Skaug (2000), found that miswak users - a stick or root of the species Salvadora persica with antibacterial properties used as a toothbrush across Africa - had less gingival bleeding in the molars than toothbrush users, as well as lower prevalence rates of $\geq 4 \mathrm{~mm}$ pocketing and attachment loss. This study also found that the prevalence of attachment loss was higher in the posterior maxillary teeth, with the opposite true for the mandible. The use of the miswak appears to improve oral hygiene (Halawany, 2012), most probably by cleaning the dental plaque away from the gums and reducing the microbial load. Although little is known of dental hygiene practices in the Neolithic, Kerma, or Medieval periods in Nubia, the high prevalence seen in the molar region in these collections, as well as those of Coimbra and Scottish Medieval period, may point to a similar problem. The molar region can be hard to clean of food and plaque, with deposits building faster or more readily than in other regions of the dentition (Hillson, 2005). This would, in turn, differentially increase the microbial challenge and hypersensitive response of the host's immune system (Cekici et al., 2014; Darveau et al., 1997; Kornman et al., 1997), particularly in that part of the mouth.

The Neolithic and Kerma sites, examined in this study, also show some differences between the sexes. At site R12, the young adult males show no signs of periodontal disease, with young adult females displaying interdental changes in the molars. At the Kerma site H29, no periodontal disease was observed in the anterior teeth of both the young and middle adult males, while females present the condition in both age groups. Due to poor preservation, few individuals from R12 and H29 could be assigned age and sex, and these results may not be representative of the assemblages. In all tooth regions, the middle adults from the Medieval sites show a higher prevalence of periodontal disease in males than fe- 
males. This difference is only statistically significant in the anterior teeth from both Medieval sites (3-J-23: difference $=23.2 \%$, CID 11.3 to $33.7 \mathrm{P}=0.0002$; 3-J-18: difference $=9.0 \%$, CID 4.9 to $13.3 \mathrm{P}=<0.0001)$ and in the premolars at site 3-J-23 (difference $=19.1 \%$, CID 4.7 to $32.0 \mathrm{P}=0.012$ ). Bar these differences, little appears to separate males and females at the Medieval sites in either age category. This mirrors the findings from Coimbra. Using a $3 \times 2 \mathrm{Chi}^{2}$ test with 2 degrees of freedom, Wasterlain et al. (2011, p. 36) compared the number of interdental septa recorded as healthy, with gingivitis, and with destructive lesions between males and females. Their results indicate that males were significantly more at risk of periodontal disease and gingivitis, and less likely to have 'healthy' interdental septa. However, this particular statistical test may hide the true cause of the difference between males and females. When considered separately, males showed a lower prevalence of healthy septa than females ( $24.1 \%$ and $27.5 \%$ respectively; difference $=3.4 \%$; CID -5.1 to $-1.6 \mathrm{P}=0.0002$ ) and a higher prevalence of gingivitis than females $(61.1 \%$ and $58.9 \%$ respectively; difference $=2.3 \%$; CID 0.3 to 2.3 $\mathrm{P}=0.0253)$. Conversely, periodontal disease showed a prevalence of $14.7 \%$ in males and $13.6 \%$ in females, a modest difference of $1.1 \%$ (CID -0.3 to $2.5 \mathrm{P}=0.1312$ ) that is not statistically significant. These results appear to indicate that males had a significantly lower prevalence of 'healthy' interdental septa and a significantly higher prevalence of septa with gingivitis, but similar levels of periodontal disease. Males and females from Coimbra, however, showed a significantly higher prevalence than observed at site R12 (males difference $=9.8 \%$, CID 4.7 to $12.5 \mathrm{P}=0.0006$; females difference $=9.9 \%$, CID 4.4 to $12.4 \mathrm{P}=0.0014$ ) and a significantly lower prevalence than recorded at site 3-J-23 (males difference $=18.8 \%$, CID -22.6 to 18.1 $\mathrm{P}=<0.00001$; females difference $=7.6 \%$, CID -10.7 to $-4.6 \mathrm{P}=<0.00001)$.

Biological differences between the sexes may explain these variations in prevalence (Curilović, Mazor, \& Berchtold, 1977; Hefti, Engelberger, \& Büttner, 1981) and it has been suggested that female hormonal fluctuations may lead to a higher prevalence of periodontal disease (Holm-Peedersen \& Löe, 1967). However, other studies do not support this finding (Amar \& Chung, 1994; Kinane et al., 2001; MarshallDay, Stephens, \& Quigley Jr, 1955; Mealey \& Moritz, 2003; Shiau \& Reynolds, 2010; Sooriyamoorthy \& Gower, 1989). Indeed, in the results presented here, females in the earlier periods show higher prevalence than males in certain areas of the mouth, however, these differences are not statistically significant and prevalence in other dental regions are similar between sexes. In the later Medieval groups, it is male individuals who show statistically higher prev- alence and progress to destructive periodontal bone loss more readily than females in the older age category, particularly in the anterior dentition.

In older adults, Kerr (1991) also noted a higher prevalence of scores denoting destructive periodontal disease and suggested these were probably a reflection of a "cumulative effect" (p. 353) rather than a greater susceptibility or risk with increasing age. In essence, after destructive bone loss occurs, the loss of attachment of the periodontal ligament means that the bone is not replaced (Cochran, 2008; Hienz, Paliwal, \& Ivanovski, 2015; Hillson, 2005). As age increases, there may be a cumulative effect whether or not the lesions are active. This cumulative effect may account for some of the differences seen between the young and middle adult age categories in the current study. However, these differences were not significant in the Neolithic or Kerma period assemblages, and prevalence was only significantly higher in middle adult males in both Medieval collections. Although a higher prevalence was sometimes seen in middle adult females in the Medieval period, this was not true for every region of the dentition (see Tables 15-18). In the groups examined, the results suggest that - apart from in some Medieval cases there is little difference in the risk of developing periodontal disease, nor its cumulative effects, with increasing age.

Many factors appear to contribute to the development, progression and thus the prevalence of periodontal disease. This equifinality is further confounded by the sporadic progression and recession of the disease. Either acute or chronic progression may occur; leading to florid destruction of the alveolar bone (both localised or widespread) (Hajishengallis \& Korostoff, 2017; Page \& Schroeder, 1976). Periods of healing can restore bone texture to a certain extent, or there may be retention of bone loss despite an area being in a quiescent phase, with no hypersensitivity or destructive activity (Kerr, 1988; Page \& Schroeder, 1976). Page and Schroeder (1976) noted that a progression from an 'established lesion' to an 'advanced lesion' may occur within a couple of weeks to several years. With a lack of patient history and the cumulative effects of an episodic disease, captured at the point of death, the role of periodontal disease on the concept of 'oral health' may be hard to apply in archaeological remains. Instead, a mere snapshot of an individual's state of 'health' is actually represented. As shown here, this 'snapshot' may vary in different parts of the mouth. Standalone clinical studies also encounter this limitation and focus on recording a patient's 'periodontal status', a term also used by Kerr -perhaps in an attempt to capture the flitting nature of this complex disease. Further data is required to contextualise the differ- 
ences over time, and between sexes and ages observed here, such as the low prevalence of periodontal disease at the Neolithic site of R12. The Kerr method has been used in very few studies, despite appearing to offer the best route forward. The data presented in this study gives new insight into the periodontal status of the inhabitants of the Middle Nile region from the Neolithic to Medieval period. Continued application of the Kerr method in other archaeological assemblages from both the Nile Valley and farther afield may help to contextualise these findings further and advance current understanding of this complex disease.

\section{Acknowledgements}

This project was kindly funded by an Arts and Humanities Research Council Collaborative Doctoral Award for collaborative research between The British Museum and University College London. Photographic images of skeletal and dental elements are courtesy of The Trustees of The British Museum. We would also like to thank Dr Davies-Barrett for assistance with editing and the use of illustrative material.

\section{REFERENCES}

Acsádi, G., Nemeskéri, J., \& Balás, K. (1970). History of human life span and mortality. Budapest: Akadémiai Kiadó.

Alexandersen, V. (1967). The pathology of the jaws and the temporomandibular joint. In D. Brothwell \& A. Sandison (Eds.), Diseases in Antiquity (pp. 551-595). Spingfield: Charles C Thomas.

Altman, D., Machin, D., Bryant, T., \& Gardner, M. (2000). Statistics with confidence: confidence intervals and statistical guidelines. Bristol: J W Arrowsmith Ltd.

Altman, D. (1999). Practical statistics for medical research. Boca Ranton: CRC press.

Amar, S., \& Chung, K. M. (1994). Influence of hormonal variation on the periodontium in women. Periodontology 2000, 6(1), 79-87.

Antoine, D. (2017). Recording and analysing the human dentition. In P. Mitchell \& M. Brickley (Eds.), Updated Guidelines to the Standards for Recording Human Remains (pp. 10-13): Chartered Institute for Archaeologists.

Axelsson, P., \& Lindhe, J. (1981). Effect of controlled oral hygiene procedures on caries and periodontal disease in adults: results after 6 years. Journal of Clinical Periodontology, 8(3), 239-248.

Bahrami, G., Vaeth, M., Wenzel, A., \& Isidor, F. (2017). Marginal Bone Loss after Ten Years in an Adult Danish Population: A Radiographic Study. Oral Health \& Preventive Dentistry, 15(2), 183-189.
Bard, K. A. (2008). An introduction to the archaeology of ancient Egypt (1 Ed.). London: Blackwell.

Barnett, M. L. (2006). The oral-systemic disease connection: An update for the practicing dentist. The Journal of the American Dental Association, 137, 5-6.

Bawadi, H. A., Khader, Y. S., Haroun, T. F., AlOmari, M., \& Tayyem, R. F. (2011). The association between periodontal disease, physical activity and healthy diet among adults in Jordan. Journal of Periodontal Research, 46(1), 74-81.

Belting, C. M., Massler, M., \& Schour, I. (1953). Prevalence and incidence of alveolar bone disease in men. The Journal of the American Dental Association, 47(2), 190-197.

Berkovitz, B. K. B., Holland, G. R., \& Moxham, B. J. (1977). A colour atlas and text of oral anatomy, histology and embryology (Second ed.). London: Wolfe Publishing Ltd.

Bjorn, H., Hailing, A., \& Thyberg, H. (1969). Radiographic assessment of marginal bone loss. Odontologisk Revy, 20, 165-179.

Björnsson, M. J., Velschow, S., Stoltze, K., HavemosePoulsen, A., Schou, S., \& Holmstrup, P. (2003). The influence of diet consistence, drinking water and bedding on periodontal disease in SpragueDawley rats. Journal of Periodontal Research, 38(6), 543-550.

Bonnet, C. (2004). The Kerma Culture. In D. Welsby \& J. Anderson (Eds.), Sudan Ancient Treasures (pp. 70-77). London: British Museum Press.

Bonnet, C. (2010). Forty years research on Kerma culture. Paper presented at the 4th Cataract and Beyond: Proceedings of the 12th international conference for Nubian studies, British Museum, London.

Brooks, S., \& Suchey, J. M. (1990). Skeletal age determination based on the os pubis: a comparison of the Acsádi-Nemeskéri and Suchey-Brooks methods. Human Evolution, 5(3), 227-238.

Buikstra, J. E., \& Ubelaker, D. H. (1994). Standards for data collection from human skeletal remains. Proceedings of a seminar at the Field Museum of Natural History Fayetteville Arkansas Archaeological Survey(44).

Cekici, A., Kantarci, A., Hasturk, H., \& Van Dyke, T. E. (2014). Inflammatory and immune pathways in the pathogenesis of periodontal disease. Periodontology 2000, 64(1), 57-80.

Chaix, L. (1984). Troisième note sur la faune de Kerma (Soudan) 1 Campagnes 1985 et 1984. Nubian Studies, 32, 31-34.

Chaix, L. (2007). Contribution to the knowledge of domestic cattle in Africa: the osteometry of fossil Bos taurus L. from Kerma, Sudan (2050-1750 BC). In G. Grupe \& J. Peters (Eds.), Skeletal Series and Their Socio-economic Context: Documenta Ar- 
chaeobiologiae 5 (pp. 170-249). Rahdan: Verlag M. Leidorf.

Chaix, L., \& Grant, A. (1992). Cattle in ancient Nubia. Anthropozoologica, 16, 61-66.

Clapham, A. J., \& Rowley-Conwy, P. A. (2007). New discoveries at Qasr Ibrim, Lower Nubia. In R.T. Cappers (Ed.), Fields of Change: Progress in African Archaeobotany. (pp. 157-164). Groningen:

Barkhuis \& Groningen University Library.

Cochran, D. L. (2008). Inflammation and bone loss in periodontal disease. Journal of Periodontology, 79 (8S), 1569-1576.

Corbet, E. F., Ho, D. K. L., \& Lai, S. M. L. (2009). Radiographs in periodontal disease diagnosis and management. Australian Dental Journal, 54, S27S43.

Costa, R. L. (1982). Periodontal disease in the prehistoric Ipiutak and Tigara skeletal remains from Point Hope, Alaska. American Journal of Physical Anthropology, 59(1), 97-110.

Curilović, Z., Mazor, Z., \& Berchtold, H. (1977). Gingivitis in Zurich schoolchildren. A reexamination after 20 years. Schweizerische Monatsschrift fur Zahnheilkunde= Revue mensuelle suisse d'odonto -stomatologie, 87(8), 801-808.

Darout, I. A., Albandar, J. M., \& Skaug, N. (2000). Periodontal status of adult Sudanese habitual users of miswak chewing sticks or toothbrushes. Acta Odontologica Scandinavica, 58(1), 25-30.

Darveau, R. P., Tanner, A., \& Page, R. C. (1997). The microbial challenge in periodontitis. Periodontology 2000, 14(1), 12-32.

Davies, D. M., \& Picton, D. C. A. (1969). A study of the periodontal state in two hundred and two skulls of primitive peoples. Journal of Periodontal Research, 4(3), 230-234.

Davies, D. M., Picton, D. C. A., \& Alexander, A. G. (1969). An objective method of assessing the periodontal condition in human skulls. Journal of Periodontal Research, 4(1), 74-77.

Dennison, D. K., \& Dyke, T. E. (1997). The acute inflammatory response and the role of phagocytic cells in periodontal health and disease. Periodontology 2000, 14(1), 54-78.

Elamin, A. M., Skaug, N., Ali, R. W., Bakken, V., \& Albandar, J. M. (2010). Ethnic disparities in the prevalence of periodontitis among high school students in Sudan. Journal of Periodontology, 81 (6), 891-896.

Eshed, V., Gopher, A., \& Hershkovitz, I. (2006). Tooth wear and dental pathology at the advent of agriculture: New evidence from the Levant. American Journal of Physical Anthropology, 130(2), 145-159. doi:10.1002/ajpa.20362

Fish, E. W. (1948). Surgical pathology of the mouth. London: Pitman.
Friedman, R. (2007). The Nubian cemetery at Hierakonpolis, Egypt. Results of the 2007 Season. The C-group cemetery at locality HK27C. Sudan $\mathcal{E}$ Nubia, 11, 57-71.

Fuller, D. Q. (2004). Early Kushite agriculture: Archaeobotanical evidence from Kawa. Sudan $\mathcal{E}$ Nubia, 8, 70-74.

Fuller, D. Q., \& Edwards, D. N. (2001). Medieval plant economy in Middle Nubia: preliminary archaeobotanical evidence from Nauri. Sudan $\mathcal{E}$ Nubia Bulletin, 5, 97-103.

Gautier, A., \& Van Neer, W. (2011). The fauna of Kadero and the arrival of pastoralism in the Nile Valley of Central Sudan. In M. Chłodnicki, M. Kobuseiwicz, \& K. Kroeper (Eds.), Kadero (pp. 375-408). Inwroclaw: Poznan.

Geethika, M., \& Chava, V. K. (2016). Nutrition and periodontal disease. Annals $\mathcal{E}$ Essences of Dentistry, 8(3), 1-7.

Global Burden of Disease, G. B. D. (2017). 2016 Disease and Injury Incidence and Prevalence Collaborators: Global, regional, and national incidence, prevalence, and years lived with disability for 328 diseases and injuries for 195 countries, 1990-2016: a systematic analysis for the Global Burden of Disease Study 2016. The Lancet, 390, 1211-1259.

Godlewski, W. (2010). The Kingdom of Makuria. Paper presented at the fourth cataract and beyond; proceedings of the 12th international conference for Nubian studies, British Museum, London.

Grant, A. (2002). Food, status and social hierarchy. In P. Miracle \& N. Milner (Eds.), Consuming Passions and Patterns of Consumption (pp. 17-23). Oxford: McDonald Institute for Archaeological Research.

Gröndahl, H. G., \& Gröndahl, K. (1983). Subtraction radiography for the diagnosis of periodontal bone lesions. Oral Surgery, Oral Medicine, Oral Pathology, 55(2), 208-213.

Haaland, R. (1987). Socio-economic differentiation in the Neolithic Sudan (Vol. 350). London: BAR.

Hajishengallis, G., \& Korostoff, J. M. (2017). Revisiting the Page \& Schroeder model: the good, the bad and the unknowns in the periodontal host response 40 years later. Periodontology 2000, 75 (1), 116-151.

Halawany, H. S. (2012). A review on miswak (Salvadora persica) and its effect on various aspects of oral health. The Saudi Dental Journal, 24 (2), 63-69.

Hassan, F. A. (1986). Desert environment and origins of agriculture in Egypt. Norwegian Archaeological Review, 19(2), 63-76.

Hausmann, E., Allen, K., \& Clerehugh, V. (1991). What alveolar crest level on a bite-wing radio- 
graph represents bone loss? Journal of Periodontology, 62(9), 570-572.

Hausmann, E., Ortman, L. F., \& Sedransk, N. (1979). Experimental alveolar bone loss in the monkey evaluated by 125 I absorptiometry. Calcified Tissue International, 29(1), 133-139.

Hefti, A., Engelberger, T., \& Büttner, M. (1981). Gingivitis in Basel schoolchildren. Schweizerische Monatsschrift fur Zahnheilkunde= Revue mensuelle suisse d'odonto-stomatologie, 91(12), 1087-1092.

Heijl, L., Rifkin, B. R., \& Zander, H. A. (1976). Conversion of chronic gingivitis to periodontitis in squirrel monkeys. Journal of Periodontology, 47 (12), 710-716.

Hienz, S. A., Paliwal, S., \& Ivanovski, S. (2015). Mechanisms of bone resorption in periodontitis. Journal of Immunology Research, 2015, 1-10.

Hillson, S. (2005). Teeth (2nd ed.). Cambridge: Cambridge University Press.

Holm-Peedersen, P., \& Löe, H. (1967). Flow of gingival exudate as related to menstruation and pregnancy. Journal of Periodontal Research, 2(1), 13-20.

Hujoel, P. P., \& Lingström, P. (2017). Nutrition, dental caries and periodontal disease: a narrative review. Journal of Clinical Periodontology, 44(S18), 79-84.

Iacumin, P., Bocherens, H., Chaix, L., \& Marioth, A. (1998). Stable carbon and nitrogen isotopes as dietary indicators of ancient Nubian populations (Northern Sudan). Journal of Archaeological Science, 25(4), 293-301.

Irish, J. D. (2008). Dental morphometric analysis of the Neolithic human skeletal sample from R12: characterizations and contrasts. In S. Salvatori \& D. Usai (Eds.), A Neolithic Cemetery in the Northern Dongola Reach: Excavations at Site R12 (Vol. 16, pp. 105-112): British Archaeological Reports Limited.

Irish, J. D. (2010). The human skeletal remains from Gebel Ramlah: A physical anthropological assessment. In M. Kobusiewicz, J. Kabaciński, R. Schild, J.D. Irish, M.C. Gatto \& F. Wendorf (Eds.), Gebel Ramlah, Final Neolithic Cemeteries from the Western Desert of Egypt (pp. 191-224). Poznań: Institute of Archaeology and Ethnology, Polish Academy of Sciences, Poznań Branch.

Kennedy, J. E. (1974). Effect of inflammation on collateral circulation of the gingiva. Journal of Periodontal Research, 9(3), 147-152.

Kennedy, J. E., \& Polson, A. M. (1973). Experimental marginal periodontitis in squirrel monkeys. Journal of Periodontology, 44(3), 140-144.

Kerr, N. W. (1986). Dental examination of the Aberdeen Carmelite collection: late Medieval 13001600. In E. Cruwys \& R. Foley (Eds.), Teeth and Anthropology (Vol. 291, pp. 189): BAR.
Kerr, N. W. (1988). A method of assessing periodontal status in archaeologically derived skeletal material. Journal of Paleopathology, 2(2), 67-78.

Kerr, N. W. (1991). Prevalence and natural history of periodontal disease in Scotland-the mediaeval period (900-1600 AD). Journal of Periodontal Research, 26(4), 346-354.

Kikuta, J., Wada, Y., Kowada, T., Wang, Z., SunWada, G., Nishiyama, I., \& Kumanogoh, A. (2013). Dynamic visualization of RANKL and Th17-mediated osteoclast function. The Journal of Clinical Investigation, 123(2), 866-873.

Kinane, D. F., Podmore, M., \& Ebersole, J. (2001). Etiopathogenesis of periodontitis in children and adolescents. Periodontology 2000, 26(1), 54-91.

Kornman, K. S., \& di Giovine, F. S. (1998). Genetic variations in cytokine expression: a risk factor for severity of adult periodontitis. Annals of Periodontology, 3(1), 327-338.

Kornman, K. S., Page, R. C., \& Tonetti, M. S. (1997). The host response to the microbial challenge in periodontitis: assembling the players. Periodontology 2000, 14(1), 33-53.

Kronfeld, R. (1933). Histopathology of the teeth and their surrounding structures. Philadelphia: Lea \& Febiger.

Krzyżaniak, A. (2011). Neolithic cemetery. In M. Chłodnicki, M. Kobuseiwicz, \& K. Kroeper (Eds.), Kadero (pp. 57-72). Inwroclaw: Poznań.

Krzyżaniak, L. (2004). Kadero. In D. Welsby \& J. Anderson (Eds.), Sudan: Ancient Treasures (pp. 4953). London: British Museum Publications.

Kuper, R., \& Kröpelin, S. (2006). Clime-controlled Holocene occupation in the Sahara: motor of Africa's evolution. Science, 313(5788), 803-807.

Kuper, R., Möhlig, W., Bollig, M., \& Bubenzer, O. (2007). Environmental change and cultural history in northeastern and southwestern Africa. In O. Bubenzer, A. Bolton, \& F. Darius (Eds.), Atlas of Cultural and Environmental Change in Arid Africa (pp. 8-11). Köln Heinrich-Barth-Institut.

Laine, M. L., Crielaard, W., \& Loos, B. G. (2012). Genetic susceptibility to periodontitis. Periodontology 2000, 58(1), 37-68.

Lavigne, S. E., \& Molto, J. E. (1995). alSystem of measurement of the severity of periodontal disease in past populations. International Journal of Osteoarchaeology, 5(3), 265-273.

Löe, H. (1965). Periodontal changes in pregnancy. Journal of Periodontology, 36(3), 209-217.

Löe, H. (2000). Oral hygiene in the prevention of caries and periodontal disease. International Dental Journal, 50(3), 129-139.

Lovejoy, C. O., Meindl, R. S., Pryzbeck, T. R., \& Mensforth, R. P. (1985). Chronological metamorphosis of the auricular surface of the ilium: a 
new method for the determination of adult skeletal age at death. American Journal of Physical Anthropology, 68(1), 15-28.

Lukacs, J. R. (1989). Dental paleopathology: methods for reconstructing dietary patterns. In M. Iscan \& K. Kennedy (Eds.), Reconstruction of Life from the Skeleton (Vol. 1, pp. 261-286). New York: A.R. Liss.

Macklin, M., \& Woodward, J. (2001). 2. Holocene alluvial history and the palaeochannels of the river Nile in the Northern Dongola Reach. In D. Welsby (Ed.), Life on the Desert Edge: Seven Thousand Years of Settlement in the Northern Dongola Reach, Sudan (Vol. I, pp. 7-13). Baisingstoke: Baisingstoke Press.

Marshall-Day, C. D., Stephens, R. G., \& Quigley Jr, L. F. (1955). Periodontal disease: prevalence and incidence. Journal of Periodontology, 26(3), 185203.

Masotti, S., Onisto, N., Marzi, M., \& Gualdi-Russo, E. (2013). Dento-alveolar features and diet in an Etruscan population (6th-3rd c. BC) from northeast Italy. Archives of Oral Biology, 58(4), 416-426.

Mealey, B. L., \& Moritz, A. J. (2003). Hormonal influences: effects of diabetes mellitus and endogenous female sex steroid hormones on the periodontium. Periodontology 2000, 32(1), 59-81.

Meller, C., Urzua, I., Moncada, G., \& Von Ohle, C. (2009). Prevalence of oral pathologic findings in an ancient pre-Columbian archeologic site in the Atacama Desert. Oral Diseases, 15(4), 287-294.

Murphy, T. (1959). Compensatory mechanisms in facial height adjustment to functional tooth attrition. Australian Dental Journal, 4(5), 312-323.

Newman, H. N., \& Levers, B. G. (1979). Tooth eruption and function in an early Anglo-Saxon population. Journal of the Royal Society of Medicine, 72 (5), 341-350.

Offenbacher, S., Barros, S. P., \& Beck, J. D. (2008). Rethinking periodontal inflammation. Journal of Periodontology, 79(8S), 1577-1584.

Page, R. C. (1998). The pathobiology of periodontal diseases may affect systemic diseases: inversion of a paradigm. Annals of Periodontology, 3(1), 108120.

Page, R. C., \& Eke, P. I. (2007). Case definitions for use in population-based surveillance of periodontitis. Journal of Periodontology, 78(7S), 13871399.

Page, R. C., \& Schroeder, H. E. (1976). Pathogenesis of inflammatory periodontal disease. A summary of current work. Laboratory Investigation; A Journal of Technical Methods and Pathology, 34(3), 235-249.

Papapanou, P. N., \& Wennström, J. L. (1991). The angular bony defect as indicator of further alveo- lar bone loss. Journal of Clinical Periodontology, 18 (5), 317-322.

Papapanou, P. N., Wennström, J. L., \& Gröndahl, K. (1988). Periodontal status in relation to age and tooth type: a cross-sectional radiographic study. Journal of Clinical Periodontology, 15(7), 469-478.

Person, P. (1961). Diet consistency and periodontal disease in old albino rats. Journal of Periodontolo$g y, 32(4), 308-311$.

Persson, R. E., Rollender, L. G., Laurell, L., \& Persson, G. R. (1998). Horizontal alveolar bone loss and vertical bone defects in an adult patient population. Journal of Periodontology, 69(3), 348356.

Petersen, P., \& Ogawa, H. (2012). The global burden of periodontal disease: towards integration with chronic disease prevention and control. Periodontology 2000, 60(1), 15-39.

Petersen, P. E. (2003). The World Oral Health Report 2003: continuous improvement of oral health in the 21st century-the approach of the WHO Global Oral Health Programme. Community Dentistry and Oral Epidemiology, 31, 3-24.

Petersen, P. E., Bourgeois, D., Ogawa, H., EstupinanDay, S., \& Ndiaye, C. (2005). The global burden of oral diseases and risks to oral health. Bulletin of the World Health Organization, 83, 661-669.

Phenice, T. W. (1969). A newly developed visual method of sexing the os pubis. American Journal of Physical Anthropology, 30(2), 297-301.

Rams, T. E., Listgarten, M. A., \& Slots, J. (2018). Radiographic alveolar bone morphology and progressive periodontitis. Journal of Periodontology, 89(4), 424-430.

Research-Science-Therapy-Committee. (2003). Position paper: Diagnosis of periodontal diseases. Journal of Periodontology, 74(8), 1237-1247.

Rogers, T., \& Saunders, S. (1994). Accuracy of sex determination using morphological traits of the human pelvis. Journal of Forensic Sciences, 39(4), 1047-1056.

Russell, A. L. (1956). A system of classification and scoring for prevalence surveys of periodontal disease. Journal of Dental Research, 35(3), 350-359.

Salvatori, S., \& Usai, D. (2008a). Bright and colourful: the stone jewels of R12 males females, adults and young: A Neolithic cemetery in the northern Dongola reach: excavations at Site R12 (Vol. 16). Oxford: British Archaeological Reports Limited.

Salvatori, S., \& Usai, D. (2008b). A Neolithic cemetery in the northern Dongola Reach: excavations at Site R12 (Vol. 16): British Archaeological Reports Limited.

Schwartz, Z. V. I., Goultschin, J., Dean, D. D., \& Boyan, B. D. (1997). Mechanisms of alveolar bone 
destruction in periodontitis. Periodontology 2000, 14(1), 158-172.

Shiau, H. J., \& Reynolds, M. A. (2010). Sex differences in destructive periodontal disease: a systematic review. Journal of Periodontology, 81(10), 1379-1389.

Sooriyamoorthy, M., \& Gower, D. B. (1989). Hormonal influences on gingival tissue: relationship to periodontal disease. Journal of Clinical Periodontology, 16(4), 201-208.

Thoden van Velzen, S. K., Abraham-Inpijn, L., \& Moorer, W. R. (1984). Plaque and systemic disease: a reappraisal of the focal infection concept. Journal of Clinical Periodontology, 11(4), 209-220.

Thomas, R. (2008). The origin and use of ceramics on the islands od Mis and Umm Muri, in the Late Meroitic to Christian periods. Sudan \& Nubia, 12, 64-73.

Tilakaratne, A., Soory, M., Ranasinghe, A. W., Corea, S. M. X., Ekanayake, S. L., \& de Silva, M. (2000). Periodontal disease status during pregnancy and 3 months post-partum, in a rural population of Sri-Lankan women. Journal of Clinical Periodontology, 27(10), 787-792.

von Wowern, N., Klausen, B., \& Kollerup, G. (1994). Osteoporosis: a risk factor in periodontal disease. Journal of Periodontology, 65(12), 1134-1138.

Wasterlain, S. N., Cunha, E., \& Hillson, S. (2011). Periodontal disease in a Portuguese identified skeletal sample from the late nineteenth and early twentieth centuries. American Journal of Physical Anthropology, 145(1), 30-42.

Watson, A. D. J. (1994). Diet and periodontal disease in dogs and cats. Australian Veterinary Journal, 71(10), 313-318.

Welsby, D. (1996). The Kingdom of Kush: The Napatan and Meroitic Empires. London: British Museum Press.

Welsby, D. (2001). 14. Results and Analysis. In D. Welsby (Ed.), Life on the Desert Edge: Seven Thousand Years of Settlement in the Northern Dongola Reach, Sudan (pp. 568-610). Baisingstoke: Baisingstoke Press.

Welsby, D. (2002). The medieval kingdoms of Nubia: pagans, Christians and Muslims along the Middle Nile. London: British Museum Press.

Welsby, D. (2003). Survey above the Fourth Cataract (Vol. 10). Basingstoke: The Basingstoke Press

Welsby, D. (2012). Medieval cemetery 3-J-23. SARS Draft Reports.

Welsby, D., \& Daniels, C. M. (1991). Soba: archaeological research at a medieval capital on the Blue Nile. London: British Institute in Eastern Africa

Welsby, D. A., Macklin, M. G., \& Woodward, J. C. (2002). Human responses to Holocene environmental changes in the Northern Dongola Reach of the Nile, Sudan. In R. Friedman (Ed.), Egypt and Nubia: Gifts of the Desert. The British Museum Press, London (pp. 28-38). London: British Museum Press.

Wengrow, D., Dee, M., Foster, S., Stevenson, A., \& Bronk Ramsey, C. (2014). Cultural convergence in the Neolithic of the Nile Valley: a prehistoric perspective on Egypt's place in Africa. Antiquity, 88(339), 95-111.

Whiting, R. (2018). The physical anthropology. In D. Welsby (Ed.), A Kerma Ancien cemtery in the Northern Dongola Reach: excavations at site H29 (pp. 149-201). Oxford: Archeopress Publishing Ltd.

World-Health-Organization. (2013). Oral health surveys: basic methods. Paris: World Health Organization.

Ziskin, D. E., \& Nesse, G. J. (1946). Pregnancy gingivitis: history, classification, etiology. American Journal of Orthodontics and Oral Surgery, 32(6), A390-A432. 